\title{
IDEAS DE LOS JÓVENES ESPAÑOLES ACERCA DEL PASADO RECIENTE: EL CASO DE LA TRANSICIÓN A LA DEMOCRACIA
}

\author{
Spanish Youth Ideas about the Recent Past: \\ The Case of the Transition to Democracy
}

María Sánchez-Agustí

almagosa@sdcs.uva.es

\section{Rosendo Martínez-Rodríguez}

rosendo.martinez@sdcs.uva.es

Diego Miguel-Revilla

dmigrev@sdcs.uva.es

Esther López-Torres

esterlop@sdcs.uva.es

Universidad de Valladolid. España

Fecha de recepción: 11/02/2019

Fecha de aceptación: 04/07/2019

Resumen: La condición de pasado vivo de la Historia reciente, en la que están presentes memorias enfrentadas, confiere un extraordinario valor formativo a los procesos históricos más próximos, como la Transición española a la democracia. No obstante, estudios previos en España evidencian que los profesores no suelen conceder demasiado tiempo ni atención a esta parcela de la Historia. De ahí el interés del presente estudio, cuyo objetivo consiste en analizar las teorías implícitas de los adolescentes acerca del establecimiento de la democracia en España, al finalizar la educación obligatoria. Para ello se ha diseñado una investigación de carácter mixto cuali-cuantitativo, interrogando a 913 estudiantes de ocho ciudades españolas a través de un cuestionario de preguntas abiertas y cerradas, donde el alumnado tuvo que seleccionar una opción de entre varias y, a continuación, justificar o explicar su elección. Los datos han sido procesados cuantitativamente con el software SPSS, y cualitativamente con ATLAS.ti. Los resultados demuestran que los jóvenes entienden la necesidad de un periodo de tiempo para adecuar las estructuras políticas al nuevo sistema democrático a través de la negociación 
entre fuerzas políticas, con el objetivo de llegar a pactos y acuerdos, aunque no siempre apliquen estas ideas al contexto actual. Llama la atención que una parte importante de ellos perciban el proceso como violento, una idea alejada de la visión historiográfica mayoritariamente presente en los libros de texto, que interpreta la Transición como un periodo histórico modélico, exportable a otros contextos.

Palabras clave: Educación histórica; Educación Secundaria; Historia reciente; Transición a la democracia.

Abstract: The condition of recent history as a living past, where conflicting memories are present, confers an extraordinary value to the more recent historical events, such as the Spanish transition to democracy. However, studies carried out in Spain evidence that teachers do not usually spend too much time or attention to this historical period. Hence, the interest of this study, whose aim is to analyze the adolescents' implicit theories regarding the institution of democracy in Spain, after finishing compulsory education. To this end, a mixed qualitative-quantitative research design has been used, interrogating 913 students from eight different Spanish cities by making use of a questionnaire of open and close-ended questions, where they had to select one of several options and then justify or explain their choice. The information has been quantitatively processed and examined with the SPSS software, and qualitatively analyzed with ATLAS.ti. Results show that adolescents understand the need for a time period to adapt political structures to the new democratic system through negotiation between political forces, with the objective of achieving an agreement, although they do not always apply these ideas to the current context. It is striking that a significant part of them perceive it as a convulsive process, an idea that contrasts with the historiographic vision that is predominant in textbooks, and that interprets the Transition as an exemplary historical period, exportable to other contexts.

Keywords: history education; secondary education; recent history; transition to democracy.

SUMARIO: 1. Introducción: Historia reciente y enseñanza. 2. Propósitos del estudio. 3. Aspectos metodológicos. 4. Presentación de resultados. 4.1. ¿Necesaria o no? La Transición como periodo con personalidad propia. 4.2. Violenta o pacífica: ¿dos caras de una misma moneda? 4.2.1. La visión violenta de la Transición. 4.2.2. La visión pacífica de la Transición. 4.3. ¿Reforma o ruptura? La transición pactada. 4.4. Transición y formación ciudadana. 5. Discusión de los resultados. 6. Conclusiones. 7. Financiación. 8. Referencias bibliográficas.

\section{INTRODUCCIÓN: HISTORIA RECIENTE Y ENSEÑANZA}

En la siguiente investigación nos ocupamos de analizar las teorías implícitas del alumnado sobre un tema de Historia de fragrante actualidad, la transición de la dictadura a la democracia en España. Examinar los conocimientos y las concepciones que los estudiantes han adquirido sobre la Historia nos ayuda a entender mejor los procesos de enseñanza-aprendizaje de esta materia. Cuando, además, se trata de un tema de Historia reciente de interés general y con características controvertidas, como es el periodo que aquí nos ocupa, el análisis adquiere otras aristas que tienen que ver con el tratamiento social y educativo de la Historia y sus usos públicos (Cuesta, 2000; Pasamar, 2003).

Quizá por eso, debido a este carácter controvertido y complejo, la Historia reciente es en la actualidad una materia de estudio preferente para los historiadores. 
Al mismo tiempo, es también objeto de debate social y mediático y, por consiguiente, ha ido conquistando un interés creciente en el ámbito educativo.

Entendida, desde una perspectiva dinámica, como aquella que estudia los procesos del pasado que forman parte de la experiencia de generaciones activas en el presente (Aróstegui, 2004), la Historia reciente aglutina una serie de características que la distinguen de otros periodos históricos y hacen de su estudio y su enseñanza un campo particular. Especialmente diferenciador es el hecho de que la Historia reciente forme parte de la memoria y de que los acontemientos y procesos que estudia se mezclen, a veces sin solución de continuidad, con los debates sociales, políticos y mediáticos de la actualidad. De manera que esta no solo se define por criterios temporales, sino también por aspectos sociopolíticos, subjetivos y cambiantes que interrogan al pasado más cercano en busca de los orígenes de los problemas actuales, apelando en ocasiones a temas fuertemente controvertidos (o controversiales) de difícil tratamiento en el aula (Carretero y Borrelli, 2008).

Estas características multiplican su intensidad cuando el objeto de estudio es un proceso histórico determinante y condicionador de nuestra realidad actual, como es el caso de la transición democrática en España. La Transición es un tema histórico de radiante actualidad, sobre todo por su conexión con problemáticas actuales que son objeto de debate, como la reforma de la Constitución, la continuidad de la Corona y otros aspectos institucionales y económicos que configuran nuestra realidad democrática. Desde un punto de vista historiográfico, pocos temas han producido tal cantidad de literatura y, además, desde miradas tan dispares que van desde la más absoluta complacencia con el proceso a las críticas encarnizadas (De la Gala, 2017; Ortiz, 2004; Pasamar, 2014).

Entre otros aspectos, tanto la producción historiográfica como aquella mediática suelen poner en cuestión elementos clave del periodo, como el propio proceso de reforma, la gestión de la memoria y de la justicia transicional, o la continuidad de elementos institucionales y económicos del régimen (Gallego, 2008; Kovras, 2014). Entre estos debates están los que hemos seleccionado para valorar las concepciones de los estudiantes sobre la Transición: la necesidad de este periodo de transición para alcanzar la democracia, el valor de la reforma frente a la ruptura, y la interpretación de esos años como violentos o pacíficos.

Precisamente, estos componenes problemáticos que despiertan tanto interés social y académico son los que convierten a los temas de Historia reciente en un arma de doble filo en el campo educativo. Por un lado, se sabe que la gestión de este tipo de periodos en el aula puede ser particularmente compleja por la multitud de fuentes y perspectivas, y por la cercanía temporal de los acontecimientos que estudia. No en vano, la Historia más reciente y conflictiva es a veces relegada de los currículums en aquellos países donde todavía no existe el suficiente consenso social y, en los peores casos, es objeto de usos tendenciosos (Paulson, 2015). 
De hecho, los temas de Historia reciente no siempre son bien recibidos por el profesorado. La falta de tiempo para vehicular currículos cronológicos inabarcables y la falta de "historicidad» por tratarse de un periodo vivenciado por muchos docentes son los principales argumentos esgrimidos para justificar la falta de atención prestada a estos contenidos (Aceituno, 2011a; Paéz-Camino, 2006; Toledo, Magendzo, Gutiérrez, e Iglesias, 2015). En algunos casos, los profesores advierten que la Historia reciente, por su conexión con el presente, es demasiado compleja para trabajarla en el aula (Martínez-Rodríguez, 2014), y cuando la trabajan, lo hacen simplificando los relatos y evitando la problematización del pasado, lo que limita las finalidades de su enseñanza (Martínez-Rodríguez, Sánchez-Agustí, y Muñoz-Labraña, 2019).

No obstante, en el ámbito de la educación histórica se suele señalar que la Historia más conflictiva puede y debe trabajarse en el aula, siempre y cuando entendamos su enseñanza, no como la transmisión de un relato, sino como una tarea intelectual de análisis del pasado (Carretero, 2017). Desde esta perspectiva, la Historia reciente nos brinda una buena oportunidad para trabajar sobre periodos cortos en el tiempo, y sobre aspectos muy interesantes como la multiperspectividad o el análisis de las causas y consecuencias.

Gracias a la cercanía temporal, la Historia reciente puede ser abordada, precisamente, con múltiples fuentes accesibles, variadas y atractivas para el aula. Entre ellas, la memoria, que resulta de enorme utilidad cuando es entendida y trabajada como fuente histórica, diferenciada de otras formas como la memoria histórica. Así, la memoria se convierte en un estímulo para el desarrollo del pensamiento histórico, que permite analizar el pasado a nivel individual y social, combinando diferentes escalas y perspectivas (Prats, 2008).

En el caso particular de la transición democrática, se trata de un periodo que, además, aglutina contenidos y conceptos fundamentales para el aprendizaje de la Historia y el desarrollo de competencias históricas y ciudadanas. Como señala Araya, el proceso español ha sido entendido como un modelo que «no sólo definió el uso del concepto, también definió modos de conceptualizar el problema (ruptura, pacto, ruptura pactada) y preferencias analíticas (roles de élites, transacciones y pactos)» (2011, p. 10). De esta manera, su estudio nos brinda una oportunidad para trabajar conceptos de segundo orden, transversales a la investigación histórica y útiles para el análisis de la realidad política y social actual.

El debate, el diálogo, la negociación o el consenso son conceptos que atañen a una educación en valores y que se ejemplifican históricamente en el proceso de transición dictadura-democracia, al mismo tiempo que nos permiten ponerlos en relación con polémicas del tiempo presente. Esta conexión con la actualidad hace que, al trabajar la Historia, se tenga la oportunidad de analizar también problemas controvertidos del presente, utilizando para ello las estrategias del historiador (Miguel-Revilla y Sánchez-Agustí, 2018). De este modo, causas y consecuencias podrían 
ser trabajadas desde múltiples perspectivas y con fuentes diversas y contrapuestas, un aspecto de gran relevancia en el caso de transiciones pactadas como la española, a la que se suele culpar de algunas de las «imperfecciones» del sistema democrático actual y, muy especialmente, de una mala gestión de la memoria, basada en el olvido (Kovras, 2014). La Historia se puede convertir así en una herramienta privilegiada para el análisis social, produciendo aprendizajes activos que hagan a los estudiantes interrogar al pasado para interpretar con criterio el presente y orientar sus acciones de una manera reflexiva hacia el futuro (Rüsen, 2004).

La propia normativa del Ministerio de Educación español, reguladora de las competencias educativas, afirma que la competencia cívica "se basa en el conocimiento crítico de los conceptos de democracia, justicia, igualdad, ciudadanía y derechos humanos y civiles», y señala el conocimiento de los acontecimientos contemporáneos como fundamentales para su consecución (Orden ECD/65/2015). Ciertamente, la Historia contemporánea ha ido acaparando un mayor protagonismo en la enseñanza durante las últimas décadas, deslizando la atención de la acción docente hacia este periodo de la Historia que llega hasta la actualidad, al considerar que el análisis de la Historia más cercana favorece la comprensión del complejo mundo en el que vivimos. Pero, ¿cómo se están percibiendo este tipo de periodos y qué conocimientos y concepciones poseen los estudiantes? Esta es la pregunta que nos hacemos en el presente trabajo, centrándonos en el caso particular de la transición a la democracia.

\section{PROPÓSITOS DEL ESTUDIO}

Como hemos avanzado, en esta investigación nos proponemos analizar las teorías implícitas de los estudiantes en torno al proceso de transición de la dictadura franquista a la democracia, al finalizar la educación obligatoria. A este respecto, entendemos que las teorías implícitas son un conjunto organizado de conocimientos que se manifiestan como una red más o menos interconexionada de proposiciones, y cuya finalidad no solo es comprender y explicar situaciones, sino también planificar acciones y comportamientos (Rodrigo, Rodríguez y Marrero, 1993).

Hemos de tener en cuenta que este marco explicativo no siempre es coincidente con las teorías propias de la disciplina, ni con los conocimientos enseñados en las aulas, sino que es el resultante de las experiencias individuales y colectivas de los sujetos. Los marcos de actuación y las fuentes de información se han diversificado extraordinariamente en las últimas décadas. La escuela ha dejado de ser la portadora exclusiva de la llamada «verdad científica», entrando en competición con otros ámbitos de comunicación, especialmente los grandes medios e Internet. Hoy más que nunca se puede afirmar que una cosa es lo que se enseña y otra lo que se aprende. 
De ahí la importancia de conocer las ideas de los estudiantes sobre este periodo tan cercano de nuestra Historia, puesto que explican, en alguna medida, su grado de concienciación histórica en el sentido señalado por Rüsen (2004), esto es, sus actitudes como ciudadanos ante problemas del presente y sus perspectivas de futuro. El destacado papel que adquieren las competencias en el currículo, como una forma de ligar los saberes escolares a su aplicación en la vida cotidiana, hace necesario examinar la manera en la que los estudiantes piensan la Historia, con la finalidad de avalar, reformular o repensar la práctica docente.

Concretamente, de este objetivo general se desprenden otros más específicos:

- Identificar si los jóvenes entienden el paso de un sistema político dictatorial a otro democrático como un proceso complejo de cambio que precisa de tiempo para producirse (ligado a los conceptos de cambio y continuidad).

- Analizar si perciben la Transición como un periodo caracterizado por la violencia o, por el contrario, como un proceso pacífico, y valorar si los argumentos en los que basan sus percepciones son históricos o ahistóricos.

- Examinar el valor conferido a los pactos y acuerdos en el éxito de la resolución de los problemas de la Transición, y comprobar cómo extrapolan estos elementos a su vida cotidiana actual.

\section{ASPECTOS METODOLÓGICOS}

En esta investigación hemos optado por un método mixto en el que se integran datos cuantitativos y cualitativos, siguiendo una estrategia de obtención concurrente de la información. Se trataría del primer nivel de posibles combinaciones entre lo cualitativo y lo cuantitativo, plenamente aceptado hoy en día en la investigación educativa, y cuya finalidad sería incrementar la comprensión del fenómeno que se investiga, buscando la convergencia de los resultados, su clarificación y sus posibles contradicciones o paradojas (Biesta, 2017).

El instrumento utilizado para la recogida de datos ha sido un cuestionario de preguntas mixtas donde se combinan las respuestas cerradas con la explicación o justificación de la opción escogida. Los datos cuantitativos han sido procesados a través del software Statistical Package for the Social Sciences (SPSS), lo que nos ha permitido organizar, analizar y mostrar los resultados de manera rápida y eficiente mediante tablas de frecuencia y porcentajes. El tratamiento de la información cualitativa se ha efectuado a través de la técnica de análisis de contenido, mediante un proceso de codificación inductivo, apoyado por el programa ATLAS.ti.

En consecuencia, los datos numéricos ofrecen información de la frecuencia del fenómeno y su distribución por género y territorio, en tanto que las narraciones de los participantes proporcionan el verdadero acervo documental para 
conocer las ideas implícitas de los informantes en torno a la llegada a la democracia en España, y para lograr valorar su calidad interpretativa, así como sus posibles contradicciones.

El método de selección de la muestra fue de carácter intencionado no probabilístico (McMillan y Shumacher, 2010), fundamentado en el nivel de estudios y la territorialidad, dada la diversidad lingüística y cultural española. Todos los informantes habían finalizado la Educación Secundaria Obligatoria durante el curso anterior en centros educativos de ocho ciudades de siete comunidades autónomas. Para su selección, se buscó la representatividad de la centralidad (Madrid y Valladolid) y de la periferia (Barcelona, Bilbao, Murcia, Huelva, Vigo y Santiago de Compostela), indagando sobre las posibles diferencias entre regiones en virtud de sus características históricas. En total han participado 913 estudiantes, entre 16 y 17 años de edad, de los cuales el 53,5 por ciento son mujeres y el 46,5 por ciento varones.

\section{PRESENTACIÓN DE RESULTADOS}

\section{1. ¿Necesaria o no? La Transición como periodo con personalidad propia}

En primer lugar, de acuerdo con uno de los objetivos principales de la investigación, se interrogó a los participantes sobre la propia naturaleza de la transición política como proceso histórico necesario para conseguir el tránsito de una dictadura a una democracia y, por tanto, sobre su percepción acerca del carácter o finalidad intrínseca de este periodo.

Atendiendo a los resultados obtenidos, tal y como puede observarse en la Tabla 1, un 77,4 por ciento del alumnado encuestado identifica el proceso de transición a la democracia como periodo bisagra con características particulares, y es capaz de diferenciarlo de las etapas anteriores y posteriores en las que se inserta. Tanto un abultado número de alumnas $(78,1$ por ciento) como de alumnos (76,7 por ciento) lo perciben como un periodo absolutamente necesario para caminar desde un sistema dictatorial a otro donde, no solo la política, sino también el resto de instituciones que articulan el Estado, puedan desenvolverse democráticamente, sin llegar a apreciarse grandes diferencias entre ambos colectivos. 
Tabla 1. Respuestas a la primera pregunta: «¿Piensas que el paso de una dictadura a una democracia se habría producido sin un proceso de transición?»

\begin{tabular}{llrrrr}
\hline & & $\begin{array}{r}\text { Respuestas válidas } \\
(\mathbf{n}=795)\end{array}$ & $\begin{array}{r}\text { Respuestas totales } \\
(\mathbf{n}=913)\end{array}$ \\
& & $\mathbf{n}$ & $\%$ & $\mathrm{n}$ & $\begin{array}{r}\text { \% } \\
\text { Pregunta 1 }\end{array}$ \\
& Sí & 88 & 11.1 & 88 & 9.6 \\
& No & 707 & 88.9 & 707 & 77.4 \\
& No contesta & & & 118 & 12.9 \\
\hline
\end{tabular}

Nota. $\mathrm{n}=$ número de respuestas.

Tampoco es posible detectar diferencias de calado si se atiende a los contrastes entre ciudades, exceptuando el caso de los encuestados de Murcia, donde un porcentaje importante (un 23,4 por ciento) opta por no contestar a esta cuestión, triplicando a los que en Valladolid se inclinan por esto mismo, tal y como se aprecia en la Figura 1. Quizás el carácter multicultural del colectivo de estudiantes murcianos podría haber influido en un mayor desapego hacia esta cuestión.

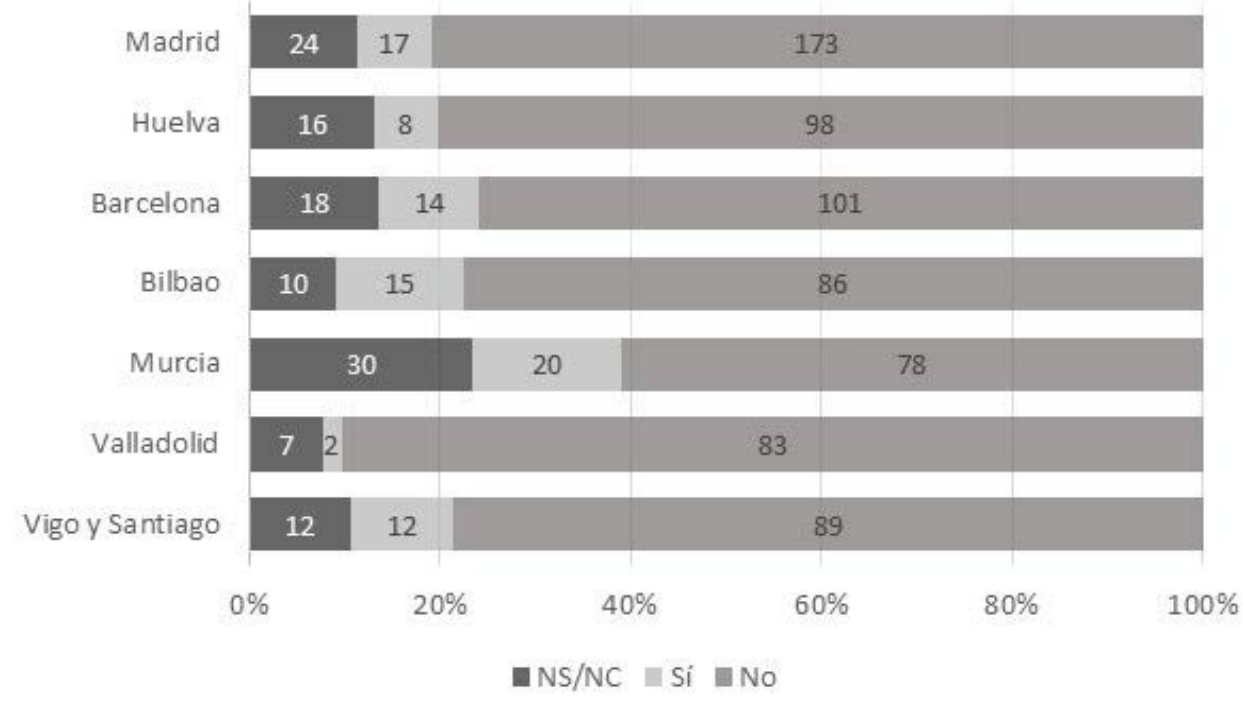

Figura 1. Resultados comparados según la ciudad a la primera pregunta: «¿Piensas que el paso de una dictadura a una democracia se habría producido sin un proceso de transición?».

Para comprender con mayor profundidad las opiniones, estas cifras deben ser complementadas con las argumentaciones proporcionadas por los estudiantes. Es por esta razón por la que se categorizan las justificaciones que estos esgrimen para apoyar la necesidad o la no necesidad de los procesos de transición a la democracia. Desde este punto de vista, se han analizado las contestaciones de los 693 alumnos y 
alumnas que trataron de articular sus pensamientos respecto a esta pregunta ( 220 dejaron el espacio en blanco), siendo posible detectar una serie de tendencias de gran interés, como se observa en la Tabla 2. El 91,3 por ciento de estas argumentaciones (es decir, 633 alumnos y alumnas) se corresponde con aquellas que justifican la necesidad del proceso de transición, mientras que solo un 8,7 por ciento (60 estudiantes) son las que explican las razones de quienes no lo perciben de esta manera.

Tabla 2. Distribución de los 913 participantes según la categorización en ATLAS.ti de los argumentos utilizados en las respuestas abiertas a la primera pregunta

\begin{tabular}{llrr}
\hline Categoría & Tipo de argumentos & n & \% \\
\hline & Obligatoriedad de un tiempo de adaptación & 388 & 56.0 \\
& Importante para evitar la confrontación & 44 & 6.4 \\
& Equilibrio de las fuerzas existentes & 30 & 4.3 \\
& Clave para la llegada de la democracia & 28 & 4.0 \\
\multirow{4}{*}{ Periodo necesario } & Incidencia en los pactos y acuerdos & 23 & 3.3 \\
& Papel relevante de la sociedad en el proceso & 19 & 2.7 \\
& Rol de Juan Carlos I en el proceso & 10 & 1.4 \\
& Otros & 58 & 8.4 \\
& Argumentos sin coherencia & 33 & 4.8 \\
\cline { 2 - 4 } & Total & 633 & 91.3 \\
\hline \multirow{5}{*}{ Periodo no necesario } & 19 & 2.7 \\
& Llegada de la democracia por medios revolucionarios & 16 & 2.3 \\
& Paso a la democracia como proceso automático & 13 & 1.9 \\
& Muerte del dictador como elemento suficiente & 6 & .9 \\
& Influencia de Europa en la llegada de la democracia & 6 & .9 \\
\cline { 2 - 4 } & Argumentos sin coherencia & 60 & 8.7 \\
\cline { 2 - 4 } & Total & 693 & 100 \\
\hline Total respuestas válidas & & 13 & \\
\hline
\end{tabular}

Nota. 220 respuestas en blanco (24.1 por ciento del total de 913).

El grupo más numeroso (388 encuestados, o un 56 por ciento del total de aquellos estudiantes que expresan su opinión por escrito) incide en la necesidad de un tiempo de adaptación entre situaciones o contextos. Estos se refieren a la idea de que los cambios sociales y políticos no se producen «de la noche a la mañana» o "de un día a otro», sino que necesitan de un periodo de tiempo o de un intervalo más o menos amplio para la transformación. Ahora bien, bajo ese paraguas se cobijan argumentos muy variados, que merece la pena distinguir. Los razonamientos más simples, defendidos por un total de 211 estudiantes, son aquellos que aluden, de manera descontextualizada, a la necesidad de un tiempo para que las cosas cambien, como un elemento requerido por necesidad o simplemente por principio. Esto podría ser aplicado como norma a cualquier situación, con argumentaciones eminentemente no históricas, como puede observarse en los siguientes ejemplos: 
[304.MU.M] Para todo tiene que haber un proceso. No se puede cambiar de un día para otro.

[086.VI.F] Porque no se puede pretender cambiar el sistema de un país de un día a otro sin un proceso de «preparación y adaptación».

[740.MD.M] Porque no se pueden cambiar de la noche a la mañana. Todo proceso necesita un tiempo.

[141.VA.F] Porque no se puede pasar directamente de «blanco a negro», entre medias hay muchos "grises».

Otro tipo de argumentaciones dentro de este gran grupo sí aluden, sin embargo, al contenido de las acciones y reformas que fueron necesarias para que el país pudiera funcionar democráticamente. En estas ocasiones (un total de 99), se suele hacer hincapié en la importancia de adaptar el sistema, las instituciones y los diferentes actores (como, por ejemplo, los partidos políticos) a la nueva situación. Aquí, tal como exponen los siguientes jóvenes, el tiempo de adaptación ya no se concibe como una necesidad alejada de un contexto específico, sino que se identifica como un elemento ineludible para transformaciones políticas de calado:

[504.BC.M] El paso de una dictadura a una democracia necesita un proceso de transición, ya que se debe reformar toda la legislación, crear una constitución, organizarse en partidos políticos, etc.

[696.HU.M] Porque no se puede pasar de un sistema político a otro asín [sic] como asín [sic]. Se debe elegir a los nuevos representantes, reformas políticas... todo esto conlleva un proceso de tiempo.

[882.MA.F] Porque se tiene que cambiar o quitar leyes, y esto que este deacuerdo [sic] los ciudadanos, reformar el gobierno.

También hay un bloque muy numeroso de estudiantes (78 en total) que justifican una transición como el periodo de tiempo necesario para cambiar, no las instituciones y organismos políticos, sino la mentalidad de la gente. Desde este punto de vista, la «minoría de edad» del pueblo español precisaría de un proceso madurativo para asimilar las nuevas pautas de vida:

[158.VA.F] Porque la gente tenía que acostumbrarse a un cambio, no podrían asimilarla [la democracia] rápidamente.

[562.BC.M] Porque en todo gran cambio hay una transición, la gente no se duerme estando en una dictadura y se levanta en una democracia, sino que su pensamiento tiene que evolucionar.

[090.VI.F] Porque para todo gran cambio tiene que haber un tiempo de adaptación y cambios. La gente tarda en adaptarse, las cosas en hacerse y demás. 
Tras las 388 argumentaciones descritas con anterioridad, el siguiente punto de vista más repetido, aunque a bastante distancia, en esta ocasión con un total de 44 menciones (es decir, un 6,4 por ciento), no explica únicamente el proceso transicional como un tiempo para la adaptación a la nueva situación, sino que sobre todo sirve como fórmula mágica para evitar la involución o la confrontación entre españoles. El miedo a que el proceso de transición a la democracia en España terminase en una guerra civil como la de 1936, o la posibilidad de que se volviesen a recrudecer conflictos o enfrentamientos violentos es captado por estos estudiantes, que lo expresan de la siguiente manera:

[883.MD.F] Porque podía ser posible que se desencadenaran conflictos los cuales podrían terminar en una guerra civil o en el peor de los casos con otra dictadura.

[873.MD.M] Porque, si no, hubiera dado lugar a una guerra civil que haría aumentar los recelos entre la población y lo único que haría sería crear el caldo de cultivo perfecto para una dictadura.

Como vemos, para muchos de los encuestados, la Transición permitió que la sociedad y las instituciones fueran asumiendo progresivamente, y sin cambios bruscos, los nuevos modelos de convivencia, siempre con un fin en mente: organizar la sociedad española democráticamente. Junto a un grupo destacado de 30 estudiantes (un 4,3 por ciento) que centran su interés en el equilibrio de fuerzas existente en los últimos años del periodo dictatorial en España, la toma de decisiones de manera pacífica y mediante pactos y acuerdos que caracterizó el periodo es reseñada solamente entre las explicaciones de 23 de los encuestados (un 3,3 por ciento), a los que se unen otros 28 (cerca del 4 por ciento) que centran su argumentación en la llegada de la democracia:

[827.MD.M] Porque con la muerte de Franco, aún había dirigentes militares que tenían influencia sobre el gobierno. Este período de transición provocó la reflexión de la población y la llegada de acuerdos.

[051.VI.F] Porque ese proceso de transición fue indispensable para el correcto afianzamiento de la democracia en nuestro país, de una forma pacífica y apoyada por la mayoría.

Hasta aquí se han reseñado las opiniones mayoritarias, pero no son, por supuesto, las únicas encontradas, pues 19 personas (un 2,7 por ciento) focalizan la atención en el papel de la sociedad al hablar de la necesidad de un periodo de transición, y 10 más (un 1,4 por ciento) expresan su percepción sobre la enorme importancia del rol del rey Juan Carlos I como garante de este proceso de transición. A todos estos casos, se unen un total de 58 estudiantes (un 8,4 por ciento), quienes utilizan argumentos dispersos y minoritarios, así como otro conjunto de 
encuestados (un total de 33, un 4,8 por ciento) que expresa su opinión de manera taxativa, sin luego ser capaz de argumentar su posición.

Para finalizar este apartado, es importante no olvidar al grupo de jóvenes que, aunque con poco peso (60 menciones, un 8,7 por ciento), justifican que el periodo de Transición no fue una necesidad. Analizar sus argumentaciones es de interés, no por su valor cuantitativo, sino por el carácter de la mayoría de las explicaciones esgrimidas. En primer lugar, una de las opiniones encontradas más frecuentemente entre este grupo tiene que ver con una percepción de que la democracia habría llegado a nuestro país en cualquier caso y situación. Dejando a un lado seis participantes que no ofrecen argumentos con lógica, 16 de los alumnos y alumnas (un 2,3 por ciento) considera, de hecho, el paso a la democracia como algo que se podría haber producido eventual o automáticamente, como se deriva de contestaciones como las siguientes:

[623.HU.M] Una dictadura no puede durar mucho tiempo y menos si es dura.

[043.VI.F] Si todo el mundo quisiera el cambio, no sería necesario, no habría que pactar nada, todo vendría solo.

[290.MU.F] Porque antes o después hubiera pasado.

Para otros 13 estudiantes (un 1,9 por ciento), el mero hecho de la muerte del dictador constituye en sí mismo un cambio de régimen. Estos entienden que una vez fallecido, la democracia hubiera llegado de una u otra manera, sin considerar las múltiples posibilidades existentes y sobre las que la propia sociedad del momento era consciente. Para otros seis, la presión de Europa habría traído la democracia a nuestro país. Por otro lado, merece la pena destacar a 19 estudiantes (un 2,7 por ciento) que consideran que la llegada de la democracia podría haberse logrado también de forma más rápida a través de métodos revolucionarios.

[013.SA.M] Porque la gente con el paso del tiempo se revelaría [sic] y pasaría a una democracia sin transición.

[497.BC.F] Por un golpe, no se como [sic] explicarlo pero creo que hay la posibilidad.

[876.MD.M] Porque los ciudadanos estaban cansados de la dictadura y tarde o temprano se revelarían [sic].

No faltan, por último, opiniones dentro de este grupo minoritario que, aun reconociendo que la democracia pudo establecerse de manera más rápida y brusca mediante el ejercicio de la fuerza y la violencia, manifiestan que la existencia de un tiempo para la adaptación estuvo mucho mejor, algo sobre lo que se discutirá con más profundidad en el análisis de preguntas posteriores, y que, en todo caso, se hace patente en ejemplos como los seleccionados a continuación: 
[001.SA.F] Se podría haber producido pero de una forma más brusca y violenta. Yo creo que es mejor que pasara como pasó.

[570.BC.F] Creo que un tiempo para que las cosas se calmen y la gente asimile su nueva situación es recomendable, aunque poderse producir, se hubiera podido producir igual sin época de transición.

\subsection{Violenta o pacífica: ¿dos caras de una misma moneda?}

La imagen que las personas tienen sobre un periodo histórico guarda una estrecha relación con la forma de percibir la presencia o ausencia de violencia en él. Los periodos de paz en la Historia no vienen definidos por la ausencia de conflictos, sino por la forma en que estos se resuelven (recordemos que el término latino pax significa pacto), y no solo tienen que ver con el nivel de estabilidad o inquietud social, sino también en cómo esta nos compromete individualmente.

La historiografía tradicional ha interpretado la Transición en este sentido, convirtiendo "el espíritu de consenso» español en un modelo exportable a otros países en similares situaciones (Fusi, 2009; Linz, 1996). No obstante, recientemente se ha cuestionado esta visión por algunos historiadores, al poner sobre la mesa el número de muertos provocados por el terrorismo de izquierda y derecha, desmontando la visión idílica del proceso (Baby, 2018; Sánchez Soler, 2010). En atención a estas consideraciones, parece interesante saber con cuál de las dos visiones coinciden los alumnos y alumnas españoles, que fueron interrogados sobre si, a su juicio, el paso de la dictadura a la democracia se produjo de forma violenta o pacífica.

Como en el resto de ocasiones, el análisis se inicia con la cuantificación de la información recogida en relación con las contestaciones a las preguntas de respuesta cerrada. En este caso específico, tal y como se puede apreciar en la Tabla 3, los estudiantes que cumplimentaron el cuestionario se manifiestan muy divididos a la hora de decantarse por una visión más o menos pacífica de la Transición española. Ninguna de las dos opciones obtiene la mayoría absoluta si contabilizamos el 7,1 por ciento de los encuestados que tomó la decisión de no contestar. Al respecto, si bien aquellos que perciben el periodo como un proceso violento alcanzan el 41,4 por ciento, un 49,8 por ciento se decanta por una visión pacífica de la etapa. Ahora bien, si atendemos a la variable género y consideramos aisladamente a los hombres, el porcentaje que tiene una visión pacífica se eleva hasta el 54,4 por ciento, frente al de las mujeres que es del 45,9 por ciento, tal y como puede observarse en la Tabla 4. 
Tabla 3. Respuestas a la segunda pregunta: «¿Cómo consideras que se produjo el paso de la dictadura a la democracia en nuestro país?»

\begin{tabular}{llrrrr}
\hline & & $\begin{array}{r}\text { Respuestas válidas } \\
(\mathrm{n}=848)\end{array}$ & & $\begin{array}{r}\text { Respuestas totales } \\
\text { (n=913) }\end{array}$ \\
& & $\mathrm{n}$ & $\mathrm{n}$ & $\begin{array}{r}\text { \% } \\
\text { Pregunta } 2\end{array}$ \\
& Violentamente & 378 & 44.6 & 378 & 41.4 \\
& Pacíficamente & 455 & 53.7 & 455 & 49.8 \\
& Ambas & 15 & 1.8 & 15 & 1.6 \\
& No contesta & & & 65 & 7.1 \\
\hline
\end{tabular}

Nota. $\mathrm{n}=$ número de respuestas.

Tabla 4. Respuestas, según el género de los encuestados, a la segunda pregunta: «¿Cómo consideras que se produjo el paso de la dictadura a la democracia en nuestro país?»

\begin{tabular}{llrrrr}
\hline & & & $\begin{array}{r}\text { Mujeres } \\
(\mathrm{n}=488)\end{array}$ & $\begin{array}{r}\text { Hombres } \\
(\mathrm{n}=425)\end{array}$ \\
& & $\mathrm{n}$ & $\%$ & $\mathrm{n}$ & $\begin{array}{r}\text { \% } \\
\text { Pregunta 2 } 212\end{array}$ \\
& Violentamente & 213.4 & 166 & 39.1 \\
& Pacíficamente & 224 & 45.9 & 231 & 54.4 \\
& Ambas & 10 & 2.0 & 5 & 1.2 \\
& No contesta & 42 & 8.6 & 23 & 5.4 \\
\hline
\end{tabular}

Nota. $\mathrm{n}=$ número de respuestas.

A la vez, parece relevante resaltar que, en esta cuestión, el factor territorial adquiere gran trascendencia. En todas las ciudades son minoría los jóvenes que tienen una visión violenta de la transición, excepto en el caso de Bilbao, donde el porcentaje alcanza el 49,5 por ciento frente al 38,7 por ciento del total que la entienden como pacífica, como se refleja en la Figura 2. Es obvio que el fenómeno terrorista en el País Vasco, ligado a la existencia de ETA, tiene mucho que ver con estos resultados. 


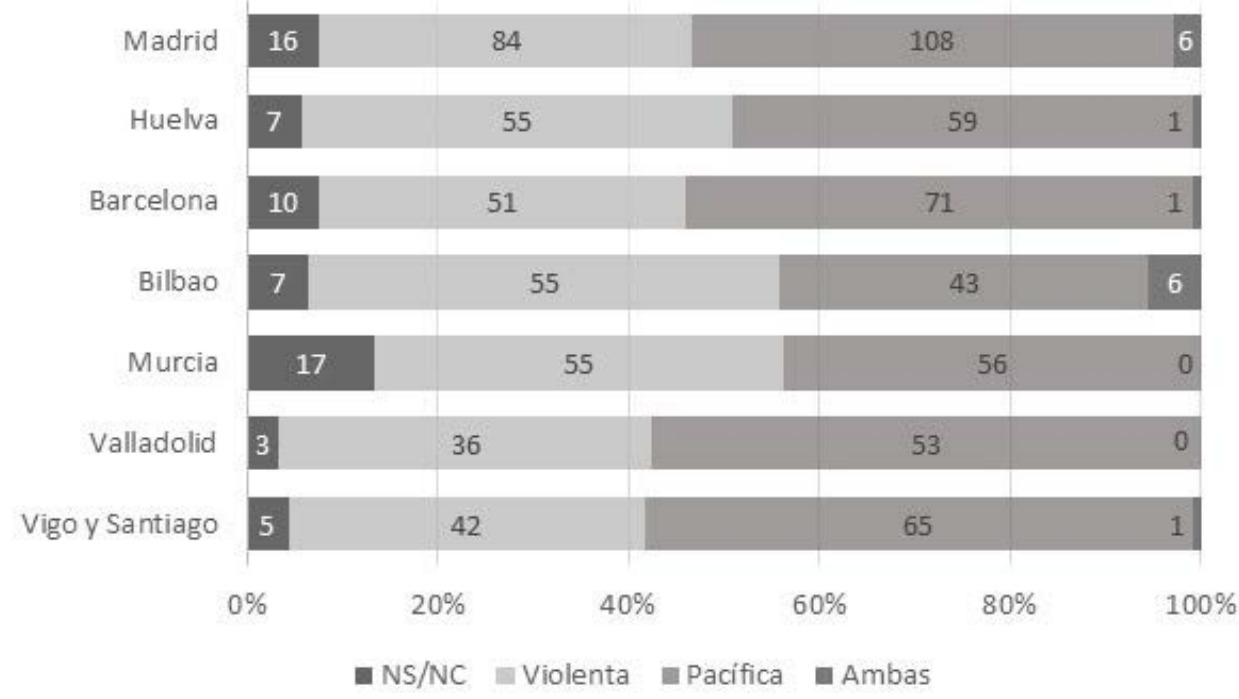

Figura 2. Resultados comparados según la ciudad a la segunda pregunta: «¿Cómo consideras que se produjo el paso de la dictadura a la democracia en nuestro país?».

Al igual que en el resto de preguntas del cuestionario, a continuación se presenta un análisis detallado de los razonamientos y argumentos utilizados por los estudiantes encuestados a la hora de defender su opinión. Resulta muy interesante conocer el grado de implantación entre los adolescentes de estas dos visiones, recogidas por la propia historiografía, pero más aún indagar sobre los argumentos que esgrimen para sostener sus ideas. En esta ocasión, es posible identificar un total de 778 redacciones proporcionadas por un número equivalente de adolescentes, 328 de las cuales (es decir, un 42,2 por ciento del total) se decantan por una visión violenta, 416 (un 53,5 por ciento) por una concepción pacífica, y las 34 restantes esgrimen argumentos que tratan de compatibilizar ambas opciones (ver Tabla 5). 
Tabla 5. Distribución de los 913 participantes según la categorización en ATLAS.ti de los argumentos utilizados en las respuestas abiertas a la segunda pregunta

\begin{tabular}{llrr}
\hline Categoría & Tipo de argumentos & n & \% \\
\hline \multirow{4}{*}{ Visión violenta } & Razonamientos contextualizados históricamente & 200 & 25.7 \\
& Razonamientos de carácter anacrónico & 80 & 10.3 \\
& Razonamientos descontextualizados & 48 & 6.2 \\
\cline { 2 - 4 } & Total & 328 & 42.2 \\
\hline & Desaparición del dictador como eje central & 130 & 16.7 \\
& Juan Carlos I como propiciador de la democracia & 69 & 8.9 \\
& Ausencia de conflictos bélicos en este periodo & 48 & 6.2 \\
& Transferencia de poder de Franco a Juan Carlos I & 47 & 6.0 \\
& Sociedad como agente del cambio & 39 & 5.0 \\
& Periodo complejo resuelto pacíficamente & 21 & 2.7 \\
& Otros pacífica & 62 & 8.0 \\
\cline { 2 - 4 } & Total & 416 & 53.5 \\
\hline Ambas visiones & & 34 & 4.3 \\
\hline Total respuestas válidas & 778 & 100 \\
\hline
\end{tabular}

Nota. 135 respuestas en blanco (14.8 por ciento del total de 913).

\subsubsection{La visión violenta de la Transición}

Comenzando por los estudiantes que interpretan el proceso de transición a la democracia en España como violento, es posible detectar, entre las 328 explicaciones obtenidas, tres tipos de argumentaciones: aquellas que se realizan de manera anacrónica (80 estudiantes, un 10,3 por ciento), aquellas que tienen en cuenta el contexto del periodo para poder defender sus ideas (200 estudiantes, un 25,7 por ciento), y las que hacen uso de argumentos descontextualizados (48 encuestados, un 6,2 por ciento).

En cuanto al primer tipo de justificaciones, las anacrónicas, es posible encontrar razonamientos en los que, tal como revelan los siguientes ejemplos, se adjudican a estos años de la Transición circunstancias propias del periodo de la dictadura franquista. De estos 80, son 35 los encuestados que hacen referencia a los periodos del hambre de la postguerra, a la autarquía, o simplemente a momentos propios de esta etapa correspondientes a las décadas de 1950, 1960 o de inicios de los años 70. Junto a ellos, otros 45 estudiantes se remontan a la Guerra Civil, a la cual aluden de forma explícita:

[873.MD.M] Porque hubieron [sic] multitud de disturbios en la época franquista en las universidades y en las calles en el contexto del momento del «mayo del 64».

[624.HU.F] La democracia se logró a partir de la Guerra Civil, en la que partidarios de la democracia y sublevados se enfrentaron para apoyar sus ideas, dando lugar a una violenta batalla. 
[416.BI.M] Miles de ejecuciones sin juicio injustificado [sic], matanzas, violaciones a los derechos humanos, condiciones infrahumanas.

[042.VI.M] En el cambio se produjo grandes enfrentamientos, hermanos que se mataban por ideas diferentes, fueron años de violencia.

Entre las explicaciones que se centran adecuadamente en el periodo de la Transición, abundan las que acusan a los militares de involucionismo y de ser los causantes del clima de inestabilidad política, especialmente en relación con el golpe de estado del teniente coronel Tejero. El asalto al Congreso es percibido como el paradigma del abuso de poder y empleo de la fuerza por 51 de ellos (un 6,6 por ciento), aunque también existen referencias a los atentados que se produjeron en la etapa (22 participantes, un 2,8 por ciento):

[030.SA.M] Violenta porque hubo un momento de inestabilidad política en el que Tejero protagonizó un golpe de Estado que puso en jaque a la democracia.

[446.BC.F] Fue un golpe de Estado cuando entra en el parlamento y pega los tiros.

[082.VI.M] Como se dice coloquialmente, no fue un camino de rosas, el ejemplo más claro de violencia es el intento de golpe de Estado de Tejero.

Llama la atención que, en estas visiones del periodo como violento, rara vez aparezca la palabra huelga, y que sean muy escasas las menciones al terrorismo, más presentes en los alumnos del País Vasco. A la vez, se hace una muy escasa alusión a manifestaciones y a la represión policial (una de ellas atribuida equivocadamente a la Guardia Civil):

[484.BC.M] Se hacían manifestaciones y la guardia civil estaba ahí presente para pegarles, ya que no tenían las mismas ideas que el dictador.

[440.BI.F] Manifestaciones del pueblo pero sin quemas, la única la de ETA.

[439.BI.M] En mi opinión es violenta ya que se produjeron diversas manifestaciones y grupos armados, como ETA, que ponían bombas.

Tampoco faltan aquellos que atribuyen la falta de estabilidad social a la confrontación ideológica entre las personas que apoyaban el cambio de sistema político y los que querían perpetuarlo. En este caso, son 72 las referencias encontradas al respecto (un 9,3 por ciento).

[039.VI.M] Porque había quien quería continuar en una dictadura y quien quería un cambio por lo que hubo muchos conflictos.

[181.VA.F] Porque había personas que defendían a la dictadura y personas que querían tener democracia. No hubo un acuerdo entre ellos. 
[444.BI.M] Tras la muerte de Franco muchas personas en el país lloraban por él, esas mismas personas luchaban por que no llegase la democracia, mientras que otros en el país salían a la calle con protestas pidiendo la libertad y el cambio a la democracia.

Merece la pena indicar que 20 jóvenes (un 2,6 por ciento) inciden en la lucha contra la dictadura, aunque en términos muy generales, otros 19 (un 2,4 por ciento), en la naturaleza (a su juicio) repentina del cambio, algo que pudo contribuir al ambiente violento, y 16 más hacen referencia a diversos aspectos no sistematizables.

Por último, dentro de los argumentos a favor de una visión violenta del periodo, y en contraste con las opiniones más o menos contextualizadas en la época de la Transición española, un grupo de estudiantes presenta argumentos genéricos que no permiten identificar el momento al que se están refiriendo. Por ejemplo, 25 de los encuestados (un 3,2 por ciento del total) inciden en la muerte de multitud de personas, aunque no suelen ir más allá de expresar el hecho de que hubo muchos fallecidos, sin llegar a entrar en la naturaleza de estas muertes:

[586.HU.F] Porque hubo muchos enfrentamientos y muchas muertes.

[426.BI.M] Mataron a mucha gente inocente.

Además de 14 encuestados que hablan en términos muy variados, se añaden nueve estudiantes que dejan de lado la Transición española para argumentar que todo cambio de sistema político implica violencia, con ejemplos como los siguientes:

[183.VA.M] Porque de estar en una dictadura a un cambio tan brusco tiene que ser violenta.

[492.BC.F] Porque no se puede pasar de una dictadura donde no tiene valor tu palabra a una democracia pacificamente [sic] ya que el dictador no lo haría.

\subsubsection{La visión pacífica de la Transición}

Entre los argumentos utilizados por los 416 estudiantes (un 53,5 por ciento) que se decantan por defender una visión de la transición a la democracia en España marcada por la ausencia de violencia, es posible encontrar una focalización en aspectos muy diversos.

En primer lugar, son mayoritarios los que aluden a la desaparición del dictador como causa fundamental de la no violencia. Para ellos, Franco muere de forma natural en la cama, y eso es suficiente para garantizar un proceso transitorio sin enfrentamientos. Esta idea es repetida por un total de 130 estudiantes (un 16,7 por ciento), con argumentos como los aquí seleccionados: 
[187.VA.M] Porque no se expulsó al jefe de Estado, sino que falleció.

[200.BA.F] La dictadura terminó con la muerte de Francisco Franco y no hubo ninguna guerra.

[519.BC.M] Cuando Franco murió empezó la democracia.

[621.HU.M] Aunque antes había habido una guerra civil y constantemente se perseguía a los que iban en contra de la dictadura, el paso fue pacífico ya que el dictador murió y se acabó la dictadura.

Como puede observarse, en este tipo de argumentaciones se detecta una concepción del alumnado que entiende la llegada de la democracia tras la muerte del dictador como algo natural, un aspecto también encontrado en las respuestas a otras de las preguntas presentes en el cuestionario aplicado. Para ellos, el hecho de que Franco falleciera por causas naturales parece garantizar el carácter pacífico del proceso, sin llegar a valorar la posibilidad de que la dictadura hubiera podido continuar por otros medios o que el paso a la democracia hubiera derivado en enfrentamientos o conflictos abiertos.

Otros 47 estudiantes (algo más del 6 por ciento) inciden de manera clara en el hecho de que Franco trasfiriera el poder al rey Juan Carlos de forma previa a su fallecimiento, entendiendo, por tanto, que el carácter pacífico del proceso viene avalado por este traspaso ordenado de poderes. En estas ocasiones, es posible encontrar razonamientos como los siguientes:

[849.MD.M] Porque Franco nombró a su sucesor y se murió por enfermedad, no por suicidio ni asesinato y el cambio no fue a la fuerza.

[666.HU.F] Fue pacífica pues antes de morir Francisco Franco ya tenía claro a quién iba a entregarle su poder, quien iba a sustituirle como Jefe de Estado.

Precisamente, el papel jugado por el rey Juan Carlos como propiciador de la llegada de la democracia de forma pacífica es destacado de manera principal por 69 estudiantes (un 8,9 por ciento). En estas ocasiones, la transición a la democracia se refleja como una decisión personalista y autónoma del monarca, pero no como un paso condicionado o determinado por el contexto del momento o por las demandas de la sociedad, tal y como reflejan las propias respuestas:

[553.BC.F] Juan Carlos I era "amigo» de Franco, entonces el rey actual le dijo que seguiría con sus pautas después de su muerte pero suerte que no lo hizo.

[204.VA.M] Porque Franco al morirse le otorgó la dictadura al Rey (Juan Carlos I) y éste le traicionó, no siguiendo con la dictadura que Franco había querido que siguiese para que España siguiese bien. Al traicionarle Juan Carlos I, fue Rey de España y se implantó una democracia. 
Por otro lado, la sociedad en su conjunto aparece como protagonista, y como agente esencial de un cambio pacífico en varias de las respuestas analizadas. En esta ocasión son 39 (es decir, algo más del 5 por ciento) las personas que hacen referencia al hartazgo de los ciudadanos, o a su papel a la hora de hacer patente la necesidad de superar la dictadura de Franco:

[829.MD.F] Porque la población estaba deseosa de tener voz y voto.

[067.VI.F] Yo creo que fue pacífico debido a la muerte de franco [sic] ya que el pueblo (la mayoría) deseaba un sistema «mejor» que para poder ser escuchado y tenido en cuenta.

Un número no desdeñable de alumnos y alumnas (un total de 48, un 6,2 por ciento) se limita a señalar la ausencia de guerras como característica esencial del periodo, aludiendo alguno de ellos, explícitamente, a la Guerra Civil:

[134.VA.F] No hubo ningún tipo de conflicto bélico.

[007.SA.M] Fue un cambio pacífico ya que no se produjo otra guerra civil para que se diera el cambio.

Junto a esto, merece la pena destacar a una pequeña parte de los estudiantes, que presentan una imagen más ajustada a la realidad histórica, admitiendo que el periodo fue complicado e inestable, pero que finalmente se saldó con éxito, por lo que se evitó el enfrentamiento entre los españoles como había sucedido en otras épocas. Este es el caso de 21 encuestados (un 2,7 por ciento), quienes hacen uso de argumentos como los siguientes:

[518.BC.F] Hubo constantes manifestaciones para expresar la opinión de grupos de personas, pero sin llegar a mucho más.

[901.MD.M] Porque no hubo apenas conflicto, alguna que otra manifestación, pero que yo sepa nada violenta.

No son, por supuesto, las únicas opiniones encontradas en el conjunto de las respuestas analizadas, ya que no faltan referencias dispersas a las elecciones, los partidos políticos, la aprobación de la Constitución u otros aspectos (34 menciones, un 4,3 por ciento), o al carácter gradual del proceso y cómo este facilitó la ausencia de violencia (citado por 11 estudiantes, un 1,4 por ciento). A su vez, también se han podido detectar unos pocos casos en los que la búsqueda de acuerdos y el debate se destaca como elemento fundamental por principio (seis menciones), en las que se compara la situación de España con la de otros países en el marco de la Primavera Árabe (otras seis menciones), o en los que erróneamente se razona que fue el propio Franco quien decidió convertir a España en una democracia (algo citado por cinco estudiantes). 
Por último, es obligado comentar que 34 alumnos y alumnas (un 4,3 por ciento) evitan pronunciarse a favor de una visión violenta o pacífica, y se decantan por proporcionar argumentos en los que tratan de señalar las dos caras de la moneda, incurriendo en algunos casos en curiosos errores históricos:

[747.MD.M] Pacífica porque ni las autoridades del gobierno ni la oposición tratará de echar (o en menos cantidad) como se dice en España, leña al fuego. Violenta: No olvidar a ETA, GRAPO, la matanza de Atocha por los legionarios de Cristo. Gente resentida porque la respuesta que esperaba debía hacerse de forma violenta, querían «ingresar» el odio.

En todo caso, es en estas respuestas donde los estudiantes tratan de matizar las opiniones más extremas, y donde parecen comprender que, efectivamente, no es posible hablar de una manera categórica sobre multitud de aspectos en la Historia, ya que los hechos no pueden amoldarse a preconcepciones limitadas:

[194.VA.M] Violenta, pero a la vez pacífica, dependiendo del punto de vista de las personas, unas se lo tomaron mal y usaron la fuerza, y otras simplemente lo aceptaron.

Como cierre, recordemos que son solo seis los estudiantes que aluden de forma espontánea a los pactos y acuerdos a la hora de valorar el carácter pacífico de la Transición. Este aspecto toma protagonismo en las dos siguientes preguntas del cuestionario, donde hacemos reflexionar a los estudiantes acerca de la importancia y el valor práctico del consenso político.

\section{3. ¿Reforma o ruptura? La transición pactada}

En toda la historiografía generada sobre la Transición a lo largo de estos años se señala la importancia de los pactos y acuerdos suscritos durante el periodo, bien sea para enfatizar su importancia en el éxito de la llegada a la democracia y convertir al proceso en un modelo (Tusell, 2000), bien sea para culpabilizarlos de las deficiencias actuales de nuestro sistema político (Navarro, 2015). Por este motivo, se estima interesante interrogar a los estudiantes sobre esta cuestión y examinar sus opiniones al respecto.

Atendiendo, en primer lugar, a las respuestas proporcionadas por los encuestados a las preguntas cerradas y procesadas cuantitativamente, estos jóvenes consideran, de una manera abrumadora, que los acuerdos tuvieron una trascendencia fundamental en la llegada de la democracia a nuestro país. Tal y como se observa en la Tabla 6, un 81,6 por ciento de los estudiantes que cumplimentaron el cuestionario se decantan por tildar de relevante el consenso político, sin que se aprecien diferencias significativas entre mujeres $(80,9$ por ciento) y hombres $(82,4$ por ciento). 
Tabla 6. Respuestas a la tercera pregunta: «¿Consideras importante para el retorno a la democracia los acuerdos políticos y los consensos sociales?»

\begin{tabular}{rlrrrr}
\hline & & $\begin{array}{r}\text { Respuestas válidas } \\
(\mathrm{n}=788)\end{array}$ & $\begin{array}{r}\text { Respuestas totales } \\
(\mathrm{n}=913)\end{array}$ \\
& & $\mathrm{n}$ & $\mathrm{n}$ & $\mathrm{n}$ & $\begin{array}{r}\text { \% } \\
\text { Pregunta 3 } 3\end{array}$ \\
& Sí & 745 & 94.5 & 745 & 81.6 \\
& No & 42 & 5.3 & 42 & 4.6 \\
& Ambas & 1 & .1 & 1 & .1 \\
& No contesta & & & 125 & 13.7 \\
\hline
\end{tabular}

Nota. $\mathrm{n}=$ número de respuestas.

Si la atención se traslada a los distintos ámbitos geográficos con los que se trabajó en el marco de esta investigación, son los estudiantes bilbaínos los que se manifiestan más contundentes en esta opinión (que se acerca al 90 por ciento), reduciendo el porcentaje de los que no contestan a los niveles más bajos de la muestra (un 6,3 por ciento), tal y como aparece reflejado en la Figura 3.

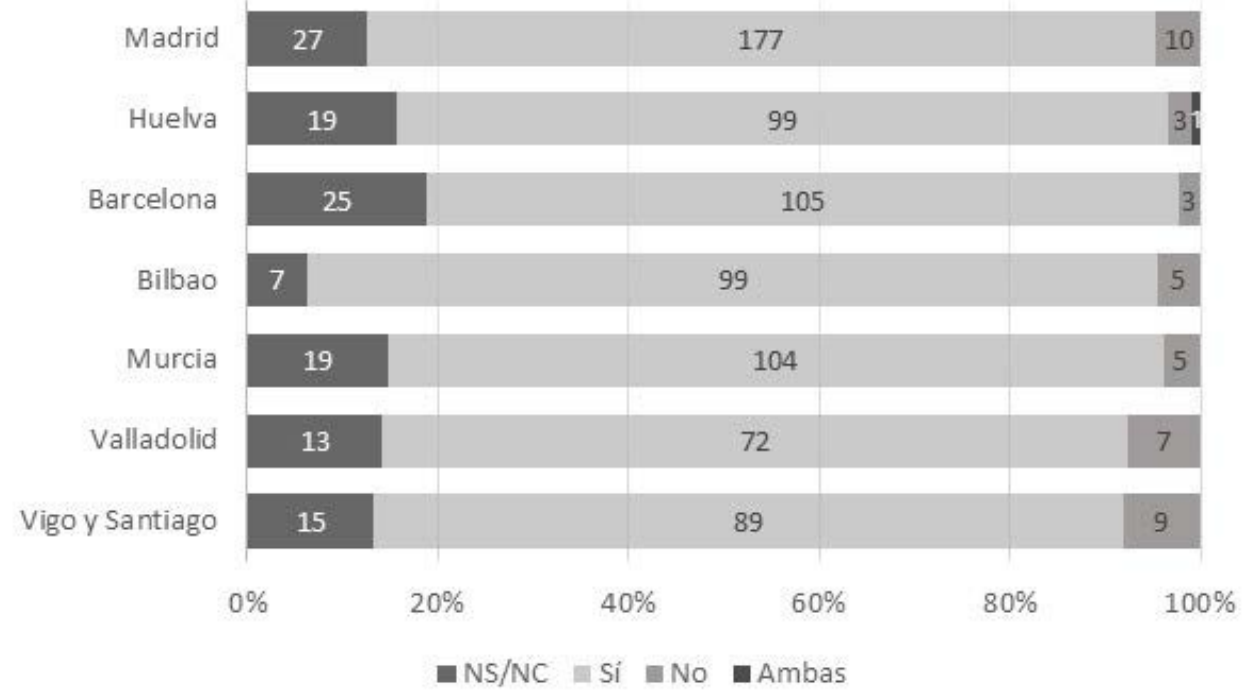

Figura 3. Resultados comparados según la ciudad a la tercera pregunta: «¿Consideras importante para el retorno a la democracia los acuerdos políticos y los consensos sociales?».

En esta ocasión son 663 los alumnos y alumnas que ofrecen una argumentación por escrito en relación con su visión particular. De estos, 628 (cerca de un 94,6 por ciento) se decantan por calificar la consecución de consensos sociales y acuerdos políticos como importantes para el retorno a la democracia. Por el otro lado, son solo 25 (un 3,9 por ciento) los estudiantes que no lo consideran de importancia, con 10 estudiantes adicionales (un 1,5 por ciento) que no logran definirse en sus respuestas (ver Tabla 7). 
Tabla 7. Distribución de los 913 participantes según la categorización en ATLAS.ti de los argumentos utilizados en las respuestas abiertas a la tercera pregunta

\begin{tabular}{llrr}
\hline Categoría & Tipo de argumentos & n & \% \\
\hline & Acuerdos necesarios para alcanzar la democracia & 149 & 22.5 \\
& Pactos y acuerdos intrínsecos al sistema democrático & 96 & 14.5 \\
& Unión y entendimiento como preferible & 91 & 13.7 \\
& Acuerdos como clave para evitar la confrontación & 65 & 9.8 \\
\multirow{4}{*}{ Relevancia de pactos } & Pactos como forma de conseguir el bienestar del país & 58 & 8.7 \\
y acuerdos & Papel de la sociedad frente a los políticos & 37 & 5.6 \\
& Incidencia en la representación de todos & 32 & 4.8 \\
& Primacía del interés general & 19 & 2.9 \\
& Énfasis en las libertades y la democracia & 17 & 2.4 \\
& Argumentos sin coherencia & 64 & 9.7 \\
\cline { 2 - 5 } & Total & 628 & 94.6 \\
\hline \multirow{3}{*}{ Irrelevancia de } & Crítica al sistema o a los políticos & 14 & 2.2 \\
pactos y acuerdos & Críticas al propio sistema democrático & 3 & .5 \\
& Otros & 8 & 1.2 \\
\cline { 2 - 5 } & Total & 25 & 3.9 \\
\hline Respuestas ambiguas & & 663 & 1.5 \\
\hline Total respuestas válidas & & 100 \\
\hline Nota. 250 raspus
\end{tabular}

Nota. 250 respuestas en blanco (27.4 por ciento del total de 913).

Comenzando el análisis con el grupo mayoritario (que tilda los acuerdos como positivos), las justificaciones que con mayor peso utilizan los adolescentes se pueden agrupar en cinco bloques: las que enfatizan que sin estos acuerdos no hubiera sido posible alcanzar la democracia, las que consideran el consenso como algo consustancial al sistema democrático, las que inciden en la unión y el entendimiento como elementos clave de una democracia, las que atribuyen al logro de pactos el carácter pacífico del proceso, y las que, por último, se centran en el desarrollo o bienestar del país desde un punto de vista general. Por supuesto, estas no son las únicas visiones, pero como se podrá observar a continuación, sí son las más frecuentemente repetidas.

En el primero de los casos, son un total de 149 estudiantes (un 22,5 por ciento de los encuestados que ofrecen explicaciones) quienes inciden especialmente en el carácter necesario de los acuerdos para alcanzar cualquier atisbo de sistema democrático. Esta es la opinión más habitual, y en la que se puede encontrar una preocupación por recalcar la búsqueda de consensos como elemento central de todo el proceso, tal y como se puede detectar en las respuestas obtenidas:

[236.MU.F] Porque si no hubiera habido esos acuerdos, hubiera seguido una dictadura porque no se habrían puesto de acuerdo.

[126.VA.F] Si no hay acuerdos no se puede decidir nada, y no se cambiaría.

[007.SA.M] Porque sin esos acuerdos España no podría haber salido de la dictadura.

[359.BI.F] Porque si no llegamos a algún acuerdo, no avanzamos. 
Muy llamativas son las justificaciones que, desvinculándose del contexto histórico, consideran que llegar a pactos es intrínseco a la democracia, y que entienden que este proceso no hubiera podido ser de otra manera, pues eso significaría que no se sería una democracia real. Para estos estudiantes (un total de 96 o, lo que es lo mismo, el 14,5 por ciento), el sistema democrático no se fundamentaría en el gobierno de la mayoría, sino más bien en la existencia de acuerdos que tengan en cuenta la opinión de todo el mundo. El consenso sería la expresión más sublime de la voluntad popular:

[895.MD.F] Sí, porque los acuerdos entre las diferentes instituciones, y partidos, son esenciales para la felicidad del pueblo y los consensos sociales también, porque sin la opinión pública y sugerencias de esta, sería imposible una democracia real.

[600.HU.M] Considero que sí, ya que si esto no se hubiera tenido en cuenta no contaría la opinión/aportación de los demás y volvería a ser una dictadura en la que la opinión del pueblo no cuenta.

[814.MD.F] Porque sin la presencia de estos, volveríamos a estar en una dictadura. Es necesario que los grupos políticos estén de acuerdo entre sí, para decidir que se supone qué [sic] es lo mejor para el pueblo, porque para algo es la democracia.

Las explicaciones ligadas al tercero de los bloques identificados se hacen eco de la idea, fuertemente tratada por la historiografía de la Transición, de que la llegada de la democracia fue posible gracias a la renuncia de todas las partes. La derecha franquista reformista y la izquierda radical, especialmente el Partido Comunista, fueron capaces de aproximar posiciones, conscientes de la envergadura de la empresa política. Así lo recogen los 91 estudiantes (un 13,7 por ciento) que destacan, ante todo, la importancia de la unión y el entendimiento entre fuerzas e ideologías muy dispares.

[422.BI.M] Se debe tener diferentes puntos de vista para poder llevar a cabo o soluciones [sic] un problema.

[694.HU.F] Si no nos escuchamos, es decir saber las opiniones y medidas de los demás no podemos llegar a acuerdos políticos por tanto si [sic] lo veo necesario para una democracia.

[202.VA.M] Si [sic] porque sin acuerdos entre la oposición y los partidarios del cambio no habría soluciones y se estarían oponiendo entre sí siempre.

A pesar de que no siempre exista una contextualización en las respuestas obtenidas, y que estas respuestas no se relacionen siempre con el periodo de la Transición, sí que permiten ofrecer una visión interesante acerca de qué elementos son valorados con mayor asiduidad por los estudiantes encuestados. En cierta manera, estas respuestas reflejan parte del "espíritu de consenso», la fórmula que garantizó un proceso en paz, evitando la confrontación entre los españoles. 
En relación con este aspecto, merece la pena atender a los 65 estudiantes (un 9,8 por ciento) que hacen referencia a los acuerdos políticos y sociales como un aspecto clave para evitar la confrontación. Estos adolescentes son, como mínimo, conscientes del fantasma de la Guerra Civil que indudablemente gravitó en las decisiones y renuncias de los políticos de la Transición, facilitando la voluntad de acuerdos que posibilitarían la concordia entre españoles y la vida en común. A la vez, también es relevante observar cómo se enfatiza, en algunos casos, el riesgo de involución y la continuidad del sistema dictatorial a través de la aplicación de la violencia. Sobre este y otros aspectos se expresan los siguientes estudiantes seleccionados a modo de ejemplo:

[827.MD.M] Sí, porque de no haber sido así, sin acuerdos, se habrían producido conflictos que habrían provocado una peor situación.

[619.HU.M] Porque si no es así, tendría que haber habido conflictos y guerras.

[088.VI.F] Porque si no estuviera todo el mundo de acuerdo, habría habido conflictos y no se podría llevar a cabo una democracia.

Otro de los aspectos más destacados por el alumnado, en esta ocasión con un total de 58 menciones (es decir, un 8,7 por ciento), se relaciona con la importancia dada por los estudiantes a los procesos de pacto y al consenso como una manera de alcanzar un mayor desarrollo o bienestar para el conjunto del país, como puede observarse en los siguientes ejemplos:

[259.MU.F] [Los acuerdos son importantes] para el bien económico, socual [sic] y político de un país y no caiga en CRISIS! [sic].

[455.BC.F] Sobretodo [sic] los acuerdos políticos, da igual elpertido [sic], con tal de hacer que funcione bien la sociedad en todos sus aspectos.

[626.HU.M] Si los políticos se unieron [sic] para trabajar de verdad por España, los problemas actuales se resolverían y la crisis desaparecería.

Finalmente, es posible detectar argumentaciones variopintas entre aquellos estudiantes que valoran positivamente la obtención de acuerdos, habiendo una buena parte de ellas que no puedan ser categorizadas debido a que expresan afirmaciones inconsistentes (64 casos, un 9,7 por ciento). Entre las que sí pueden ser agrupadas e interpretadas, destacan 37 jóvenes (un 5,6 por ciento) que inciden en el papel de la sociedad (a veces, en contraposición al de los políticos) a la hora de llegar a acuerdos, así como otros 32 (un 4,8 por ciento) que explicitan la importancia de que todos los ciudadanos estén representados en este consenso y de que su voz pueda ser escuchada. Para 19 estudiantes (un 2,9 por ciento), el interés general es aquello que parece primar por encima de todo, desde una concepción utilitarista, frente a las visiones más marcadas por principios éticos. Por último, 17 
encuestados (alrededor del 2,4 por ciento) ponen el foco en las libertades, y en el gran alivio que supone que, desde su punto de vista, los pactos propiciaron el no tener que vivir en una dictadura. A continuación se han destacado unos breves ejemplos de estas últimas ideas:

[090.VI.F] Creo que el cambio debería producirse por demanda del pueblo y no impuesto por los pensadores, sino por consenso.

[197.VA.M] El hecho de haber acuerdos es un beneficio del ciudadano porque por ejemplo un partido político no toma las decisiones que solo quería él sino que son necesarios más puntos de vista.

[325.MU.M] Si no estariamos [sic] continuamente en una dictadura en la que no habría igualdad y nadie podría expresar su opinión.

A continuación, se procede a examinar los argumentos utilizados por quienes rechazan la importancia de los pactos y acuerdos para pasar de la dictadura a la democracia, que aunque son minoritarios (tan solo justifican su respuesta 25 estudiantes, un 3,9 por ciento), resultan de interés para comprender las teorías implícitas del alumnado. Casi todas ellos se definen por un fuerte presentismo que los desvincula del contexto histórico transicional. Al respecto, la posición más frecuente, con 14 menciones, se relaciona con una crítica al sistema o a los políticos en conjunto, siempre muy influenciada por el clima social, político y mediático de los últimos años, y marcado por la crisis económica en España, pero también por la deslegitimación de los representantes públicos y la reordenación de los ámbitos de hegemonía de cada partido. Con tres menciones, las críticas al propio sistema democrático aparecen en algunas respuestas, aunque sea de una forma muy esporádica, y de ahí que no sea extraño encontrar respuestas como las siguientes a la hora de criticar el consenso y los pactos:

[388.BI.M] Porque la política es una mentira y engañan a la gente con sus chorradas y gilipolleces.

[194.VA.M] Los acuedos [sic] políticos son bobadas que solo benefician a los políticos, al pueblo nunca se les tiene demasiado o nada en cuaenta [sic], y los consensos sociales se hacen, pero a la hora de la verdad luego no sirven para nada, solo lo que digan los políticos.

[723.MD.M] Son mentira. Nunca hay acuerdo ni consenso, menos en este país. Solo intereses.

Estas visiones tan críticas hacia la política y los políticos se harán todavía más explícitas y extensas en la siguiente sección, donde se profundizará en la relación establecida entre las creencias del alumnado en torno a la política de acuerdos de la Transición española, y su actuación en el contexto actual. 
El resto de las respuestas, de nuevo muy minoritarias (ocho), no aportan demasiada información adicional. En ellas se discute el uso de la fuerza como un resorte o mecanismo de mayor utilidad, se hace una distinción entre el consenso y el acuerdo, o se hace referencia a la gradualidad de todo proceso de transición, queriendo indicar que los pactos habrían llegado eventualmente o no hubieran sido tan determinantes. A todos ellos se unen 10 participantes más (un 1,5 por ciento) que presentan argumentos ambiguos o se muestran indecisos en sus respuestas.

\subsection{Transición y formación ciudadana}

Finalmente, y con el objetivo de comprobar la manera en la que los estudiantes son capaces de extrapolar al presente sus ideas sobre el consenso expresadas en el apartado anterior, estos fueron interrogados sobre el valor concedido a los acuerdos entre partidos desde el punto de vista del contexto actual. Como en el resto de ocasiones, las respuestas a las preguntas cerradas son analizadas en primer lugar, valorando las argumentaciones y razonamientos expresados por el alumnado a continuación.

Tal y como aparece reflejado en la Tabla 8, las respuestas a la pregunta acerca de qué debe considerarse más importante si se participara en un partido político (aplicar el programa con el que se ganó las elecciones o buscar acuerdos), pueden ser calificadas como sorprendentes. Los estudiantes encuestados, que se mostraron abrumadoramente defensores de la necesidad de consensuar las decisiones políticas durante la Transición, ahora no lo perciben así, pues un 66,3 por ciento de los encuestados se decanta por aplicar el programa ganador. Solo un 28,8 por ciento de los estudiantes afirma, en cambio, que lo prioritario sería buscar acuerdos con los demás partidos en las acciones de gobierno. A esto se añade un 1,6 por ciento de los encuestados que elige ambas opciones a la vez, y un 3,3 por ciento de adolescentes que decidió no responder. Al igual que en ocasiones anteriores, en ningún caso se detectan diferencias destacables en función del género, pues únicamente el 29,3 por ciento de las alumnas y un 28,2 por ciento de los alumnos se decanta por la búsqueda de acuerdos. 
Tabla 8. Respuestas a la cuarta pregunta: «Si tú participaras en un partido político, ¿qué considerarías lo más importante?»

\begin{tabular}{llrrrr}
\hline & & $\begin{array}{r}\text { Respuestas válidas } \\
(\mathrm{n}=883)\end{array}$ & $\begin{array}{r}\text { Respuestas totales } \\
(\mathrm{n}=913)\end{array}$ \\
& & $\mathrm{n}$ & $\mathbf{0}$ & $\mathrm{n}$ & $\begin{array}{r}\text { \% } \\
\text { Pregunta 4 }\end{array}$ \\
& Aplicar programa & 605 & 68.5 & 605 & 66.3 \\
& Buscar acuerdos & 263 & 29.8 & 263 & 28.8 \\
& Ambas & 15 & 1.7 & 15 & 1.6 \\
& No contesta & & & 30 & 3.3 \\
\hline
\end{tabular}

Nota. $\mathrm{n}=$ número de respuestas.

En relación con el aspecto territorial podemos observar cómo los participantes vallisoletanos son los que se muestran más partidarios de llegar a pactos y acuerdos, aunque eso signifique sacrificar parte de su programa electoral, mientras que los gallegos son los más reticentes a renunciar a la implantación de sus propuestas políticas, como se refleja en la Figura 4.

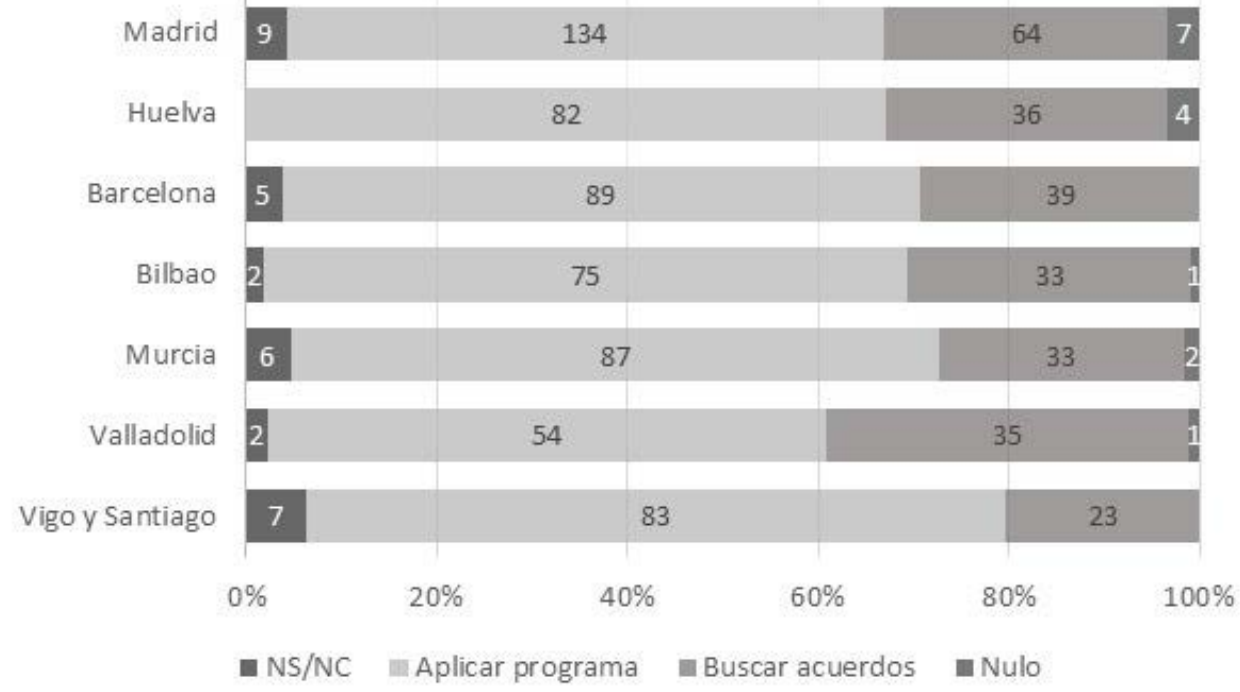

Figura 4. Resultados comparados según la ciudad a la cuarta pregunta: «Si tú participaras en un partido político, ¿qué considerarías lo más importante?».

Analizando las reflexiones proporcionadas por el alumnado, se contabilizan un total de 826 respuestas, lo que evidencia que esta pregunta ha conseguido el mayor número de contestaciones de las cuatro analizadas, probablemente por su carácter no histórico. Aunque 25 de ellas (correspondiente a un 3 por ciento de los 
encuestados que razonan su respuesta) se decantan por aplicar los programas políticos a través de acuerdos (combinando ambos aspectos), la mayoría defiende la aplicación de los programas con los que los partidos políticos fueron elegidos (564 estudiantes, un 68,3 por ciento). Por otro lado, la búsqueda de acuerdos únicamente es defendida de manera prioritaria por 237 encuestados (un 28,7 por ciento), como puede observarse en la Tabla 9.

Tabla 9. Distribución de los 913 participantes según la categorización en ATLAS.ti de los argumentos utilizados en las respuestas abiertas a la cuarta pregunta

\begin{tabular}{llrr}
\hline Categoría & Tipo de argumentos & n & \% \\
\hline & Fidelidad a la palabra y cumplimiento de promesas & 194 & 23.5 \\
& Cumplimiento programa como eje de la democracia & 137 & 16.6 \\
& Principios éticos & 77 & 9.3 \\
Aplicación del & Crítica al incumplimiento de promesas & 54 & 6.5 \\
programa electoral & Estrategia electoral como principio guía & 48 & 5.8 \\
& Reticencia o rechazo a hacer renuncias & 24 & 2.9 \\
& Mejora del país como objetivo utilitarista & 21 & 2.6 \\
& Argumentos sin coherencia & 9 & 1.1 \\
\cline { 2 - 4 } & Total & 564 & 68.3 \\
\hline & Argumentos de carácter práctico & 88 & 10.7 \\
& Lo mejor para el país o la sociedad & 49 & 5.9 \\
& Discusión como clave para la elección de lo mejor & 29 & 3.5 \\
Búsqueda de & Importancia de contentar a todo el mundo & 24 & 2.9 \\
acuerdos & Principios éticos o por principio & 22 & 2.7 \\
& Representación de toda la sociedad & 13 & 1.6 \\
& Argumentos sin coherencia & 12 & 1.4 \\
\cline { 2 - 4 } & Total & 237 & 28.7 \\
\hline Combinación de ambos aspectos & 25 & 3.0 \\
\hline Total respuestas válidas & 826 & 100 \\
\hline
\end{tabular}

Nota. 87 respuestas en blanco (9.5 por ciento del total de 913).

Comenzando por el examen de las ideas del alumnado que prima la aplicación del programa, es importante recalcar que cuando los estudiantes justifican la necesidad de cumplir las promesas electorales, fundamentalmente aluden, con argumentos más o menos elaborados, a cuestiones éticas. Aun así no todos ellos inciden en los mismos aspectos, pues la posición mayoritaria pone el énfasis en la fidelidad a la palabra y al cumplimiento de las promesas (referenciado por 194 estudiantes, un 23,5 por ciento):

[002.SA.M] Considero que lo primero es ser consecuente con las promesas electorales y cumplirlas debidamente.

[726.MD.F] Porque al fin y al cabo es por eso porque la gente me eligió. No puedes prometer cosas, simplemente para ganar y estar en el poder. Si lo dices, lo haces. 
[572.BC.F] Si durante la campaña has dicho que harías cietas [sic] cosas, tienes que cumplirlas y luchar por ellas, ya que la gente que te ha votado, lo ha hecho por tu ideología y lo que has dicho que harías.

Estos razonamientos se ven complementados por los 137 estudiantes (16,6 por ciento) que entienden el cumplimiento del programa como algo inherente al proceso democrático, y por tanto como la finalidad esencial de las elecciones:

[652.HU.F] Porque si la gente me ha votado a mi es para que aplique mi programa y por ello creo que es fundamental ver y observar los programas antes de votar.

[152.VA.F] Cumplir lo que prometiste en las elecciones porque por ello te votaron los ciudadanos. Y esa es la causa por la que estás en el poder para representarles.

[348.BI.M] Porque si es el pograma [sic] con el que he ganado las elecciones, supuestamente es lo que yo quiero hacer en el gobierno. Y si la gente me a [sic] votado será por algo.

La justificación ética no se limita a estos dos aspectos mayoritarios, ya que también es posible encontrar otras 77 referencias (un 9,3 por ciento) a aspectos como la necesidad del compromiso frente al engaño (33 casos) o la importancia de mejorar el país como un principio superior (19 nueve), entre otros aspectos. Esta última idea contrasta con los 21 estudiantes (un 2,6 por ciento) que argumentan que la mejora del país debe ser la razón por la que hacer caso a la voluntad popular, utilizando un punto de vista de carácter más utilitarista, sin convertirse en un principio ético o moral.

Es destacable la concepción de un número elevado de encuestados que entiende que no aplicar lo que un partido propone constituye un engaño a los votantes que te han elegido, y casi un auténtico fraude a la ciudadanía. Los políticos no serían, desde este punto de vista, más que los representantes del pueblo que los elige, y de ahí que no puedan defraudarlo con el incumplimiento de las promesas. Un total de 54 estudiantes (un 6,5 por ciento del conjunto) critica de manera explícita el incumplimiento de las promesas, con argumentos similares al siguiente:

[660.HU.F] Porque las personas están hartas de las promesas en las campañas electorales y luego no se cumpla cuando están en el poder. Por lo tanto intentaría cumplir lo que prometo o los propositos [sic] a los que me he comprometido.

De hecho, muchas de estas argumentaciones dejan vislumbrar un desencanto de los jóvenes ciudadanos hacia los políticos y sus formas de proceder, acusándoles explícitamente, y en algún caso con exabruptos, del incumplimiento de sus promesas electorales en beneficio propio y en detrimento de los intereses del común: 
[029.SA.M] Porque si has ganado diciendo las cosas que ibas a hacer, es necesario hacerlo porque el gobierno está para la mejora del país no para que los políticos ganen más dinero.

[264.MU.M] Aplicar lo que he dicho, y no ser un chorizo ni un cabrón como son todos los políticos.

[369.BI.F] En unas elecciones se supone que tener buenas ideas y buscar intenciones, pues si es así, deberías de intentar cumplirla. ¡PERO ES QUE NI LO INTENTAN!

[325.MU.M] Cumplir mis promesas electorales, que por eso las hice, no para engañar como lo hacen todos los políticos actualmente.

Es llamativo que un total de 48 estudiantes (un 5,8 por ciento) valoren la necesidad de cumplir el programa ganador por pura estrategia electoral, al entender que si una persona pierde la confianza de sus votantes, la próxima vez no le elegirán:

[888.MD.F] Creo que es más importante porque a mí me votarían las personas por todo aquello que prometí hacer, y si no lo hago tendría en descontento a la población y no me volverían a votar, además de que sería como «mentir» y eso me parece poco ético y moral.

[354.BI.M] De esta forma la gente podrá ver que no hay mentiras y confiaría en ti y continuaras en el gobierno [sic].

Por último, dejando a un lado nueve casos de difícil interpretación, un total de 24 encuestados (un 2,9 por ciento) habla explícitamente de la necesidad de evitar hacer renuncias, ofreciendo una visión especialmente dogmática que se aleja de cualquier intento de buscar medidas consensuadas o pactos con el resto de partidos políticos:

[346.BI.F] Si yo he ganado las elecciones con lo que yo pienso y los arreglos que quiero hacer si ganaría lo haría.

[671.HU.M] Realizaría un programa de acuerdo con mis pensamientos, ideologías y formas de ver las cosas, por ello, no tendría que esforzarme en cumplirlo, lo cumpliría porque sería como yo haría las cosas.

Desplazando la atención a los 237 estudiantes (un 28,7 por ciento) que se decantan por buscar pactos y acuerdos de manera primordial, también es posible encontrar múltiples razonamientos. Comenzando por la posición mayoritaria, es relevante destacar que 88 estudiantes (un 10,7 por ciento) aducen razones prácticas para su elección. Estas son de muy diverso tipo, pues si 29 de estos entienden que la búsqueda de acuerdos puede ser más eficaz, 12 adoptan esta posición al entender que las decisiones tomadas entre varias personas pueden ser mejores que las que 
proceden de una sola. A la vez, el resto de alumnos y alumnas hacen referencia a aspectos como la necesidad de evitar confrontaciones o el hecho de que el trabajo conjunto puede ayudar a salir de crisis como la económica, entre otros aspectos. Es posible encontrar algunos ejemplos a continuación:

[692.HU.M] Tenemos que buscar acuerdos porque todos juntos podemos hacer cambios mayores y de más importancia porque con ganar las elecciones no hay cambio sin trabajo.

[350.BI.M] Para que no hubiesen [sic] conflictos entre partidos y porque todos los partidos tienen ideas convincentes.

[676.HU.F] Buscar acuerdos con los que junto con los demás partidos se pudiera llegar a un acuerdo. No existiera ribalidad [sic] entre ellos, simplemente colaborar para lograr conseguir corregir todo los fallos aconómicos [sic], sociales y políticos que se dan.

Dejando de lado las razones de corte más práctico, es posible observar razonamientos adicionales que resultan de interés. Por ejemplo, son 49 los estudiantes (un 5,9 por ciento) que hacen referencia a la búsqueda de acuerdos entre partidos políticos como lo mejor para la sociedad en su conjunto, o para el país, considerado desde un punto de vista global. En estas argumentaciones, los encuestados asumen una visión teñida por los principios de aquello que consideran mejor para el interés general:

[666.HU.F] Buscar acuerdos, pues pueden existir ideas de otros partidos que beneficien más al país que el propio programa electoral. Llegar a un acuerdo para que todas las ideas más beneficiosas lleguen al país de alguna manera.

[867.MD.M] Pienso que llegando a acuerdos se puede conseguir una situación de bienestar común.

En cierto modo, esto complementa a los 22 estudiantes (un 2,7 por ciento) que se centran en buscar acuerdos por una cuestión de principios, o a los 24 encuestados (un 2,9 por ciento) que inciden en la importancia de conseguir un consenso que contente a todo el mundo, así como a los 13 alumnos y alumnas (un 1,6 por ciento) que pretenden favorecer la representación de todos los miembros de la sociedad, como se expresa en los siguientes ejemplos:

[126.VA.F] Conocer las opiniones del resto de partidos sería lo más adecuado para encontrar entre todos una solución y poder efectuarla. Si sólo aplicaras tu programa, posiblemente a mucha gente no le gustaría y no serías bien aceptado.

[532.BC.M] Yo creo que es más importante buscar acuerdos con los partidos, ya que significa que tu idea tiene fuerza y que es apoyada por otros grupos. En mi opinión, levar a cabo acciones sin apoyo significa que solo gustará a una pequeña parte de la población. 
En relación a la búsqueda de acuerdos, merece la pena destacar que, junto a las 12 opiniones imprecisas, son un total de 29 estudiantes (un 3,5 por ciento) quienes hacen especial hincapié en los aspectos positivos de la selección de ideas y del debate en torno a ellas, al entender, a veces de manera algo ingenua, que discutir en torno a diferentes posibilidades puede ayudar a elegir las más adecuadas:

[886.MD.F] No me gusta la política, por el hecho de ver que hay muchos partidos políticos posiblemente con grandes ideas todos, pero que sólo uno, puede llevarlas a cabo. Si fuesemos [sic] una unidad, que debatiera sus ideas y llegaran a las mejores, a lo mejor, juntos, sacariamos [sic] adelante el país.

[125.VA.F] Acordaría con los otros partidos unas determinadas acciones para mejorar el gobierno, escucharía sus ideas e intentaría buscar unas ideas que gusten a todos y con el fin de mejorar el país en vez de discutir y no llegar a ningún acuerdo.

Por último, no se puede olvidar los 25 estudiantes (un 3 por ciento) que se decantan de manera paralela por cumplir las promesas y buscar acuerdos. En estos casos, muy minoritarios, se trata de adoptar una postura más pragmática y más abierta a las diferentes posibilidades, aunque en ocasiones demasiado idealista. Al respecto, es posible consultar a continuación algunas de las respuestas obtenidas:

[322.MU.M] Para mi [sic] serían ambos acertados porque es muy importante que el pueblo vea que estás haciendo las cosas, por las que has salido elejido [sic] y la (b) es importante porque es bueno tener información de los demás partidos.

[892.MD.F] Lo principal sería cumplir lo prometido, pero otro aspecto sería intentar conseguir un acuerdo entre todos los partidos, unir todas o la mayoría de las ideas y conseguir un periodo de bien estar [sic].

\section{DISCUSIÓN DE LOS RESULTADOS}

El concepto de transición democrática ha sido definido como el periodo de tiempo que transcurre entre un régimen político autoritario que se colapsa y otro de signo distinto donde las reglas del juego no están bien definidas, ni necesariamente conducen a una democracia en toda su plenitud (O'Donell y Smither, 1988). De ahí la dificultad de delimitar con exactitud el inicio y el final de estos procesos, que pueden ser entendidos como periodos de mayor o menor duración y que, en el caso español, según la última aportación de Juliá (2017), se podría retrotraer a los inicios mismos de la dictadura.

Lo que sí está claro es que estos cambios de régimen político precisan de un tiempo para producirse, y de un periodo para cambiar estructuras e instituciones. En relación con el primer objetivo específico del estudio, así lo han entendido 
mayoritariamente estos jóvenes españoles, quienes en sus explicaciones no solo aluden al necesario cambio político e institucional, sino también a la transformación de la sociedad y su mentalidad. Habituarse a vivir, pensar y actuar con libertad comportaría, a juicio de estos alumnos y alumnas, un proceso para el que sería necesaria una suerte de "entrenamiento», y que no podría ser inmediato. Estos resultados son diferentes a los obtenidos en un estudio realizado en Chile con 616 jóvenes, donde solo un 25,6 por ciento consideró la Transición chilena como un proceso necesario para la adaptación del país al nuevo régimen (Sánchez-Agustí, Vásquez Lara, y Vásquez Leyton, 2016). No obstante, consideramos que esta diferencia puede radicar en la distinta forma de obtener la información, pues mientras que en el caso español se planteó a los estudiantes una pregunta con dos opciones entre las que debían elegir una y luego justificarla, en el estudio chileno se les pidió que definieran lo que era la Transición. Ante una disyuntiva, la memoria de reconocimiento se pone en marcha con facilidad, pero, sin apoyos, es la memoria de evocación la que entra en juego (Pozo, 2008). Se trata, pues, de un proceso mental mucho más complicado donde los elementos definitorios del concepto pueden quedar fácilmente en el olvido.

Como hemos podido apreciar, existe bastante unanimidad entre los estudiantes sobre la consideración de la Transición como periodo bisagra entre dictadura y democracia, con una personalidad propia fundamentada en la indefinición y el cambio. No obstante, atendiendo al segundo objetivo específico del estudio, este consenso desaparece a la hora de calificar el carácter del periodo, donde el grupo se fractura casi en dos mitades. Entre los que tienen una imagen pacífica del proceso podemos detectar visiones más o menos cercanas a las suministradas por la historiografía (Fusi, 2009; Linz, 1999; Tusell, 2000) y los libros de texto (Aceituno, 2011b; Martínez-Rodríguez, 2011), que identifican la Transición como modelo de actuación institucional en función del éxito de la operación y la resolución pacífica de una situación extremadamente compleja. Tal como recoge Lemus (2001), el miedo a una nueva guerra civil o a una involución del incipiente proceso democrático habría gravitado sobre la sociedad, propiciando el diálogo y el acercamiento, algo detectado por el alumnado.

Pero, sobre todo, hemos de resaltar la abrumadora cantidad de estudiantes que, a la hora de calificar el periodo, lo hacen desde planteamientos ingenuos y simplistas, alejados de toda interpretación histórica, al considerar la muerte del dictador como causa única y suficiente para garantizar un proceso en paz. Una visión idílica que no tiene en cuenta el contexto político y social de la época, y que muestra unos estudiantes con un escaso desarrollo de las habilidades ligadas al pensamiento histórico.

Tan equivocadas como las ideas anteriores están las explicaciones de los estudiantes que califican el periodo como violento, ya que un número relevante lo hacen de manera anacrónica, adjudicando a la Transición hechos y circunstancias 
de la Guerra Civil o del periodo franquista, como ya sucediera de forma parecida en la investigación realizada en Chile, donde también los estudiantes atribuyeron al proceso transitorio la violencia ejercida durante la dictadura pinochetista (Vásquez Leyton, 2014). La Transición no tendría entidad propia, siendo para estos estudiantes como una especie de epílogo de la Guerra Civil y la dictadura, con las mismas características de violencia y represión institucional de estos periodos (ejecuciones, fusilamientos, matanzas, violación de los derechos humanos, etc.).

Entre aquellos que sí identifican causas que, efectivamente, impregnaron de violencia esos años de transición, no hay referencias a las muertes por la represión policial de las numerosas manifestaciones, convocadas especialmente por sectores de la izquierda para reclamar la amnistía (cuestión que no aparece en ningún momento en los discursos estudiantiles). Así mismo, apenas mencionan los atentados terroristas del radicalismo de derechas e izquierdas que sembraron el día a día de la vida de aquellos años. Sus explicaciones, por tanto, no se hacen eco de los estudios históricos recientes que, sacando a la luz el elevado número de muertos en atentados y asesinatos de distinto signo, han catalogado la Transición (aunque también podrían haberlo hecho con el periodo democrático) como un proceso sangriento, en un intento de desmitificarlo como modelo a imitar, exportable a otros contextos (Baby, 2018; Sánchez Soler, 2010). Por otro lado, las causas de la inestabilidad y de los enfrentamientos de los que más se acercan a la realidad histórica estribarían exclusivamente en la resistencia de los franquistas (de manera genérica) al cambio, siendo el intento de golpe de estado de Tejero el momento culminante.

El carácter modélico que ha acompañado en las últimas décadas a la interpretación de la Transición española tiene como soporte clave la identificación del espíritu de consenso en el ambiente social y político de la época. Esta circunstancia no ha sido puesta en duda en ningún estudio sobre el proceso transicional, pues es una evidencia que el calado de la empresa hizo que todos consiguieran remar en el mismo sentido. Sobre este aspecto se ha centrado el tercer objetivo específico de este estudio.

Como en el caso de los jóvenes chilenos, quienes de forma mayoritaria consideraron que sin acuerdos no hubiera sido posible la democratización del país, el alumnado español se muestra consciente de que, sin este espíritu de diálogo y transacción, la sociedad española difícilmente hubiera podido transformarse en una democracia, y/o atribuyen al consenso el carácter pacífico del proceso, evitando enfrentamientos entre los ciudadanos. Además, ninguno de ellos se cuestiona el contenido de lo que se negoció (aceptación del sistema monárquico y de la simbología del Estado, especialmente), ni con quién se negoció (personalidades que habían ostentado cargos políticos durante el franquismo), como sí se ha hecho desde determinados sectores políticos de izquierda, atribuyendo a estas circunstancias las limitaciones de la democracia actual y reclamando la necesidad de una «Segunda Transición» (Navarro, 2015). 
Finalmente, debemos detenernos, por la importancia que entraña desde la perspectiva educativa y de formación ciudadana, en la gran contradicción que supone la altísima valoración de los pactos y acuerdos entre partidos durante la Transición, con sus actitudes políticas en el tiempo presente. El espíritu negociador de los políticos de la Transición es interpretado como una acción tan positiva que muchos estudiantes lo descontextualizan de la época para convertirlo en la verdadera expresión de la democracia real en cualquier tiempo y lugar, donde "la opinión de todo el mundo cuenta» porque "todos tenemos algo que decir». Ahora bien, cuando tienen que aplicarlo al momento actual, su principal exigencia a los políticos es que cumplan exactamente su programa, porque, de otra forma, estarían engañando al pueblo, faltando a la ética política y tergiversando su función como representantes. Y esta forma de pensar no es propia solo de los jóvenes españoles, pues también se manifiesta, aunque en menor medida, entre los adolescentes chilenos, quienes argumentan de similar manera señalando que las promesas de campaña deben anteponerse a cualquier otra cuestión (Vásquez Leyton, 2014).

\section{CONCLUSIONES}

De acuerdo con los datos expuestos, podemos concluir que, en su mayoría, los estudiantes españoles, al finalizar la educación obligatoria, presentan una imagen de la Transición como un periodo necesario para la adaptación a la nueva situación política, que se fundamentó en la existencia de acuerdos y compromisos entre dos sectores ideológicos, con una división de opiniones en relación a su carácter pacífico y violento. De acuerdo con estos parámetros, que presentan escasas y puntuales variaciones en función del género y el territorio, podemos calificar esta visión como un marco teórico cercano a la interpretación historiográfica predominante.

Pero cuando analizamos el conjunto de enunciados que le da sustento, observamos que estos se estructuran a través de una red inconexa de ideas simplistas, cuando no erróneas o anacrónicas, que difieren en gran manera de los argumentos manejados por la ciencia histórica. Podríamos decir que los estudiantes poseen una teoría implícita sobre el periodo en cuestión, que les permite interpretarlo sin tomar conciencia de su organización ni estructura interna, en el sentido expresado por la psicología cognitiva (Rodríguez y González, 1995). Esta característica, propia de toda teoría implícita, es posiblemente la causa de que, cuando extrapolan a su presente las «lecciones» formativas del proceso transitorio (como es la aproximación de idearios políticos a través del diálogo y la negociación), no capten la idoneidad de aplicarlo a la actualidad política y rechacen esta posibilidad, argumentando como engaño y falto de ética el incumplimiento a carta cabal del ideario programático de un partido político. 
$\mathrm{Si}$, como tradicionalmente se viene manteniendo, una de las finalidades principales de la enseñanza de la Historia es el desarrollo del pensamiento crítico en aras de formar a una ciudadanía democrática, responsable y participativa, capaz de interconectar pasado y presente, no parece que el aprendizaje de las claves de este periodo histórico sirva para ello a estos jóvenes españoles. Probablemente, como ha sido puesto de manifiesto en investigaciones realizadas, el currículo cronológico de la asignatura de Historia en cuarto curso de la ESO no ayude en este cometido (Páez-Camino, 2006). Tampoco los profesores parecen darle la importancia debida por tratarse de un periodo al que todavía se percibe como ahistórico por su cercanía (Martínez-Rodríguez, 2014) o incluso "evitable» por su carácter controvertido (Toledo, Magendzo, Gutiérrez, e Iglesias, 2015). Cabría plantearse analizar en el futuro si las teorías implícitas de los estudiantes proceden principalmente de los medios de comunicación y de la memoria familiar transmitida, tal como se ha constatado en el caso chileno (Sánchez-Agustí, Vásquez Leyton, y Vásquez Lara, 2018). De ahí su debilidad, falta de consistencia y escasa utilidad para la vida diaria.

Es necesario, pues, prestar más atención a la enseñanza de la Historia reciente, y no nos referimos tanto al espacio curricular y temporal dedicado a ella (que también), sino a los métodos con los que se lleva a cabo este proceso. Apostar de una forma más decidida por una Historia problematizada, menos memorística, de la situación española en la llegada a la democracia, contribuiría a la formación de una conciencia histórica más compleja en nuestros jóvenes. Así se constata en experiencias realizadas con el alumnado de secundaria sobre la Transición española que, inspiradas en estos principios metodológicos, han conseguido operativizar los conocimientos históricos y movilizar capacidades latentes en los estudiantes (Miguel-Revilla y Sánchez-Agustí, 2018). Pensar el pasado para actuar en el presente y orientar nuestras acciones hacia el futuro, en el sentido expresado por Rüsen (2004), debe constituir, a nuestro juicio, una prioridad en la formación obligatoria de la ciudadanía.

\section{FINANCIACIÓN}

Esta investigación ha sido financiada por el Ministerio de Economía y Competitividad del Gobierno de España a través del Proyecto TRADDEC «Estudio de las Transiciones Dictadura-Democracia: formación ciudadana y enseñanza de la Historia en el mundo escolar español y chileno» (EDU2009-09775), y del Proyecto HISREDUC «La Historia Reciente en la Educación. Diseño y evaluación de entornos digitales de aprendizaje en la enseñanza secundaria de España y Chile» (EDU2013-43782-P). 


\section{REFERENCIAS BIBLIOGRÁFICAS}

Aceituno, D. (2011a). Percepciones de los Profesores de Historia chilenos y españoles acerca del estudio de la Transición de la Dictadura a la Democracia. Perspectiva Educacional. Formación de profesores, 50(2), pp. 149-171.

Aceituno, D. (2011b). Transición y democracia: algunos datos sobre manuales escolares en 40 de la ESO. En R. López Facal (Coord.), Pensar históricamente en tiempos de globalización (pp. 15-29). Santiago de Compostela: USC.

Araya, E. (2011). Transición y Transiciones a la democracia. Sobre sentido e Historia del concepto. Íber. Didáctica de las Ciencias Sociales, Geografía e Historia, 67, pp. 10-24.

Aróstegui, J. (2004). La Historia vivida. Sobre la Historia del presente. Madrid: Alianza Editorial.

Baby, S. (2018). El mito de la transición pacífica. Violencia y política en España (1975-1982). Madrid: Akal.

Biesta, G. (2017). Mixing Methods in Educational Research. En R. J. Coe, M. Waring, L. V. Hedges, y J. Arthur (Eds.), Research Methods \& Methodologies in Education (2.. ed., pp. 159-165). London: SAGE Publications.

Carretero, M. y Borrelli, M. (2008). Memorias recientes y pasados en conflicto: ¿cómo enseñar historia reciente en la escuela? Cultura y Educación, 20(2), pp. 201-215.

Carretero, M. (2017). The Teaching of Recent and Violent Conflicts as Challenges for History Education. En C. Psaltis, M. Carretero, y S. Čehajić-Clancy (Eds.), History Education and Conflict Transformation. Cham: Palgrave Macmillan.

Cuesta, R. (2000). Usos y abusos de la educación histórica. Didáctica de las Ciencias Experimentales y Sociales, 14, pp. 23-32.

De la Gala, E. (2017). Visiones de la transición española a la democracia. Una revisión historiográfica. Tiempo Presente. Revista de Historia, 5, pp. 40-69.

Franco, M. y Levin, F. (Comp.). (2007). Historia reciente. Perspectivas y desafíos para un campo en construcción. Buenos Aires: Paidós. 
Fusi, J. P. (2009). España 1975-2008. En R. Carr, España 1808-2008 (pp. 637-670). Barcelona: Ariel.

Gallego, F. (2008). El mito de la transición. La crisis del franquismo y los orígenes de la democracia (1973-1977). Barcelona: Crítica.

Juliá, S. (2017). Historia de una política española (1937-2017). Barcelona: Galaxia Gutenberg.

Kovras, I. (2014). Truth Recovery and Transitional Justice. Deferring human rights issues. London: Routledge.

Lemus, E. (2001). En Hamelin... La Transición Española más allá de la Frontera. Oviedo: Septem Ediciones.

Linz, J. (1996). La transición española en perspectiva comparada. En J. Tusell, y A. Soto (Eds.), Historia de la transición. 1975-1986 (pp. 21-45). Madrid: Alianza Editorial

Martínez-Rodríguez, R. (2011). Historia y formación ciudadana. Un análisis a través de la transición democrática en los manuales de Educación para la Ciudadanía. En R. López Facal (Coord.), Pensar históricamente en tiempos de globalización (pp. 125-139). Santiago de Compostela: USC.

Martínez-Rodríguez, R. (2014). Profesores entre la Historia y la memoria. Un estudio sobre la Transición dictadura-democracia en España. Enseñanza de las Ciencias Sociales, 13, pp. 41-48.

Martínez-Rodríguez, R., Muñoz-Labraña, C., y Sánchez-Agustí, M. (2019). Conocimientos y creencias del profesorado y su vínculo con las finalidades de la enseñanza de la historia reciente. La transición a la democracia en España como caso controvertido. Revista de Educación, 383, pp. 11-35. doi: <https:// doi.org/10.4438/1988-592X-RE-2019-383-399>.

McMillan, J. H. y Schumacher, S. (2010). Investigación educativa. Una introducción conceptual. Madrid: Pearson Education.

Miguel-Revilla, D. y Sánchez-Agustí, M. (2018). Modelos de conciencia histórica en el alumnado de Educación Secundaria: tradición, simbología y contextualización en torno a los restos del franquismo. Panta Rei. Revista Digital de Ciencia y 
Didáctica de La Historia, 8, pp. 119-142. doi: <https://doi.org/10.6018/ pantarei/2018/6>.

Navarro, V. (2015). Ataque a la democracia y al bienestar. Crítica al pensamiento económico dominante. Barcelona: Anagrama.

O'Donell, G. y Smither P. C. (1988). Transiciones desde un gobierno autoritario. 4. Conclusiones tentativas sobre las democracias inciertas. Buenos Aires: Paidós.

Ortiz, M. (2004). Historiografía de la transición. En VV. AA., La transición a la democracia en España. Historia y fuentes documentales. VI Jornadas de Castilla La Mancha sobre investigación en archivos (pp. 223-240). Guadalajara: Anabad.

Paéz-Camino, F. (2006). Enseñar la recuperación democrática en las aulas. Consideraciones sobre la Transición en clase de Historia. Íber. Didáctica de las Ciencias Sociales, Geografía e Historia, 50, pp. 11-31.

Paulson, J. (2015). "Whether and how?» History education about recent and ongoing conflict: a review of research. Journal on Education in Emergencies, 1(1), pp. 14-47.

Pasamar, G. (2003). Los historiadores y el «uso público de la historia»: viejo problema y desafío reciente. Ayer, 49, pp. 221-248.

Pasamar, G. (2014). Los escenarios de la memoria durante la transición democrática en España: política y cultura. Historiografías, revista de historia y teoría, 7, pp. 13-33. doi: <https://doi.org/10.26754/ojs_historiografias/hrht.201472431>.

Pozo, J. I. (2008). Aprendices y Maestros. La psicología cognitiva del aprendizaje. Madrid: Alianza.

Prats, J. (2008). Memoria histórica versus Historia enseñada. Íber. Didáctica de las Ciencias Sociales, Geografía e Historia, 55, pp. 32-42.

Rodrigo M. J., Rodríguez A., y Marrero J., (1993). Las teorías implícitas. Una aproximación al conocimiento cotidiano. Madrid: Visor.

Rodríguez A. y González R. (1995). Cinco hipótesis sobre las teorías implícitas. Revista de Psicología General y Aplicada, 48(3), pp. 221-229. 
Rüsen, J. (2004). Historical Consciousness: Narrative, Structure, Moral Function and Ontogenetic Development. En P. Seixas (Ed.), Theorizing Historical Consciousness (pp. 63-85). Toronto: University of Toronto Press.

Sánchez-Agustí, M., Vásquez Lara, N., y Vásquez Leyton, G. (2016). Understanding the Processes of Transition from Dictatorship to Democracy. A Survey Among Secondary Schools Students in Chile. International Journal of Historical Learning Teaching and Research, 13(2), pp. 23-34.

Sánchez-Agustí, M., Vásquez Leyton, G., y Vásquez Lara, N. (2018). Medios de comunicación e Historia Reciente. Un estudio con alumnado chileno de secundaria. Didáctica de Las Ciencias Experimentales y Sociales, 34, pp. 19-34. doi: <https://doi.org/10.7203/DCES.34.10516>.

Sánchez Soler, M. (2010). La Transición sangrienta. Una Historia violenta del proceso democrático en España (1975-1983). Barcelona: Península.

Toledo, M. I., Magendzo, A., Gutiérrez, V., e Iglesias, R. (2015). Enseñanza de "temas controversiales» en la asignatura de historia y ciencias sociales desde la perspectiva de los profesores. Estudios Pedagógicos, 41(1), pp. 275-292.

Tusell, J. (2000, 2 de noviembre). ¿Fue modélica la Transición a la democracia? El País. Recuperado el 25 de enero de 2019, de <https://elpais.com/diario/2000/11/02/ opinion/973119611_850215.html>.

Vásquez Leyton, G. (2014). Concepciones de los estudiantes chilenos de Educación Media sobre el proceso de Transición de la Dictadura a la Democracia. (Tesis inédita de doctorado). Universidad de Valladolid. Disponible en <http://uvadoc. uva.es/handle/10324/4849>. 